\title{
Distortions in the Neoclassical Growth Model: A Cross-Country Analysis*
}

\author{
Pedro Brinca ${ }^{\dagger}$
}

August 21, 2013

\begin{abstract}
This paper investigates the properties of distortions that manifest themselves as wedges in the equilibrium conditions of the neoclassical growth model across a sample of OECD countries for the 1970-2011 period. The quantitative relevance of each wedge and its robustness in generating fluctuations in macroeconomic aggregates is assessed. The efficiency wedge proves to be determinant in enabling models to replicate movements in output and investment, while the labor wedge is important to predict fluctuations in hours worked. Modeling distortions to the savings decision holds little quantitative or qualitative relevance. Also, investment seems to be the hardest aggregate to replicate, as prediction errors concerning output and hours worked are typically one order of magnitude smaller. These conclusions are statistically significant across the countries in the sample and are not limited to output drops. Finally, the geographical distance between countries and their degree of openness to trade are shown to contain information with regard to the wedges, stressing the importance of international mechanisms of transmission between distortions to the equilibrium conditions of the neoclassical growth model.
\end{abstract}

JEL Classification: E27, E30, E32, E37

Keywords: Business cycle accounting, frictions, economic fluctuations

*I am grateful for comments from Martin Flodén, John Hassler, Tobias Broer, Alper Çenesiz, Luis Aguiar-Conraria, Alexandra Ramos, Joana Pinho, Vincenzo Quadrini, IIES, CEFUP, and GEMF seminar participants, PET2013 and the 7th Annual meetings of the PEJ conference participants and, in particular, Sirus Dehdari for excellent research assistance.

${ }^{\dagger}$ Correspondence to Pedro Brinca, email pedro.brinca@ne.su.se. Address: Department of Economics, Stockholm University, SE-106 91 Stockholm, Sweden. 


\section{Introduction}

The focus of this paper concerns the measurement and systematic analysis of different types of distortions to the equilibrium conditions of the neoclassical growth model. Their quantitative relevance in generating fluctuations at the business cycle frequency in macroeconomic aggregates is also analyzed and tentative structural explanations for such distortions are put forth by identifying relevant indicators that contain information with respect to the said distortions.

The interest in analyzing the properties of deviations from theoretically postulated relationships among macroeconomic aggregates within the neoclassical framework can be traced back at least to Solow (1957). Deviations from observed output and capital and labor inputs for a given aggregate production function were taken to be the source of long term growth and became known as the 'Solow residual' or total factor productivity. Growth accounting exercises became widespread in order to measure the contribution of each factor with respect to changes in output.

This was mainly a growth issue until Kydland and Prescott (1982) introduced a multiplicative persistent shock into an aggregate production function and managed to generate fluctuations in macroeconomic aggregates at business cycle frequencies. By then this was done in a context of a general equilibrium model, with endogenous labor supply and savings decision. Subsequent work aimed to provide structural explanations for these shocks as well as creating departures from the neoclassical growth model that could replicate fluctuations observed in the data. However, much of the focus was still on total factor productivity and in theories that could explain it.

Researchers started to be interested in the properties of deviations in other equilibrium conditions, such as the labor-leisure choice. Mulligan (2002) looks into data for the U.S. from 1889 until 1996 to describe the statistical properties of such deviations (in this case to the labor-leisure choice) and provide tentative explanations behind them. Other authors focused on models with financial frictions, such as Calstrom and Fuerst (1997) or Bernanke et al. (1999), that express themselves mostly as distortions to the savings 
decision.

Much in the fashion of growth accounting, a business cycle accounting methodology was developed by Chari et al. (2007). Distortions to the equilibrium conditions, of what the authors dub a prototype growth model containing the key ingredients of the neoclassical framework, are measured. Their quantitative and qualitative relevance in generating fluctuations in macroeconomic aggregates through a series of simulations is assessed. In the work cited, the methodology is applied to both the Great Depression and the 1981 recession in the U.S.

Since then a large body of literature has developed based on Chari et al. (2007) methodology. Some authors provide methodological departures from Chari et al. (2007). Two examples can be found in Otsu (2009) that conducts the analysis in the context of a two country model and Sustek (2010), adding a Taylor type rule for nominal interest rate setting and government bonds.

Other have applied the methodology to other countries. Kobayashi and Inaba (2006) for Japan, Simonovska and Söderling (2008) for Chile and Lamas (2009) for Argentina, Mexico and Brazil are just few examples. The results seem to conclude, much in line with Chari et al. (2007), that total factor productivity and distortions to the labor choice are relevant, where distortions to the savings decision are considerably less important. Some authors focus their analysis to one type of deviations as in Restrepo-Echavarria and Cheremukhin (2010) or Cociuba and Ueberfedt (2010) with distortions in the labor choice or other numerous studies concerning total factor productivity such as Islam et al. (2006). Finally, other line of work looks into a selected sample of countries and into specific periods of fluctuations such as output drops (see Dooyeon and Doblas-Madrid (2012) as one example).

This paper contributes to the literature in several dimensions. First the sample of countries chosen for analysis is driven purely by data availability. This avoids sample selection bias. Most business cycle accounting exercises restrict their samples by analyzing recessions, and, consequently, countries that experienced the recessive episodes. The validity of the conclusions are therefore restricted to the criteria that drove the sample selection.

Second, by taking a comparably large sample of countries and pooling the 
measured distortions cross-sectionally when analyzing specific episodes that are perceived as having an international scope such as the oil shocks in the 1970s or the 2008 financial crisis, we can draw inference as to whether such episodes systematically generated distortions in the equilibrium conditions of the neoclassical growth model across the countries in the sample.

Third, by using data that goes back until 1970 at the quarterly frequency, we can decompose the distortions in their trend and cycle components. Mulligan (2002) highlights the importance of analyzing trend and cycle separately. The author finds that marginal tax rates are important in explaining the trend but not the cycle component of distortions to the labor decision.

Fourth, by applying the business cycle accounting methodology, we are able not only to measure and decompose the distortions but also to assess their quantitative relevance in generating fluctuations in macroeconomic aggregates that resemble movements in observed data. This was performed both for specific episodes and for the whole sample, and draw inference on whether specific distortions are systematically important across the countries. We compare simulations with observed data and determine the key distortions to me modeled in order to bring the neoclassical growth model closer to reality.

Lastly, these distortions are analyzed by country characteristics, in search for indicators that contain information with respect to the distortions and in this way suggest tentative extensions to the business cycle model that are general enough to be relevant for most countries in the sample. In the last section of the paper we show that point estimates of the correlation between the the cross-country per type of wedge correlation and the geographical distance between the countries is negative for all wedges and most countries, though only in the case of the efficiency wedge there is strong statistical significance. This type of analysis is common in the trade literature, where trade between countries is often (also) explained by gravitation equations, i.e., volumes of trade as a function of the physical distance between them. The degree of openness (exports plus imports as a share of output) is another factor found to contain significant information with regard to all wedges, underlining the relevance of international mechanisms of transmission with 
regard to distortions to the equilibrium conditions of the model.

\section{Data, model and calibration}

\section{$2.1 \quad$ Data}

The data used to measure the wedges comes from OECD Economic Outlook. It concerns GDP, Government Consumption, Gross Fixed Capital Formation, Imports, Exports and their respective deflators, Total Employment and Total Hours Worked per Employee. Additionally there is also data on total population and percentage population below 16 and percentage population over 65. All series end on the last quarter of 2011 and, in very few exceptions such as some series concerning hours worked and population, data ends in the last quarter of 2010 and is extrapolated to end in 2011Q4).

Based on this, data are transformed according to the following procedure. Deflators are transformed to have 2005Q1 as base year. Data is then deflated accordingly. The four observables are output, hours worked, investment and government consumption (plus next exports), all in per-capita units. Sales and indirect taxes are not taken into account in the computation of model output because of availability and comparability. Hence, output, investment and government consumption plus net exports per capita are just the deflated series divided by quarterly interpolated active population. Hours worked are the product of Total Employment and Hours Worked per Employee divided by active population.

\section{$2.2 \quad$ Model}

The prototype economy is the same as in Chari et al. (2007). It is the neoclassical growth model with labor and savings decisions and four exogenous random variables. These variables are the efficiency wedge $A_{t}$, the labor wedge $\tau_{l t}$, the investment wedge $\tau_{x t}$ and the government wedge $g_{t}$. Consumers maximize expected utility over per-capita consumption $c_{t}$ and labor 
$l_{t}$ :

$$
\max E_{0} \sum_{t=0}^{\infty} \beta^{t} u\left(c_{t}, 1-l_{t}\right)
$$

subject to the budget constraint

$$
c_{t}+\left(1+\tau_{x t}\right) x_{t}=\left(1-\tau_{l t}\right) w_{t} l_{t}+r_{t} k_{t}+T_{t}
$$

and the capital accumulation law

$$
\left(1+\gamma_{n}\right) k_{t+1}=(1-\delta) k_{t}+x_{t}
$$

where $x_{t}$ is investment, $w_{t}$ the wage rate, $r_{t}$ the rental rate on capital, $\beta$ the discount factor, $1+\gamma_{n}$ is the population growth rate, $k_{t}$ the stock and $T_{t}$ lump sum transfers, all in per capita terms. The production function is given by $A_{t} F\left(k_{t},\left(1+\gamma_{z}\right)^{t} l_{t}\right)$ where $y_{t}$ is per capita output and $\gamma_{z}$ the rate of labor augmenting technical progress. The representative firm maximizes profits and pays factors their marginal products. The equilibrium in the economy is therefore pinned down by the aggregate resource constraint

$$
c_{t}+x_{t}+g_{t}=y_{t}
$$

where $y_{t}$ is per capita output, the production function

$$
y_{t}=A_{t} F\left(k_{t},(1+\gamma)^{t} l_{t}\right)
$$

the labor-leisure choice

$$
-\frac{u_{l t}}{u_{c t}}=\left(1-\tau_{l t}\right) A_{t}(1+\gamma) F_{l t}
$$

and the savings optimality condition

$$
u_{c t}\left(1+\tau_{x t}\right)=\beta E_{t}\left[u_{c, t+1}\left(A_{t+1} F_{k, t+1}+(1-\delta)\left(1+\tau_{x, t+1}\right)\right)\right]
$$

where a function's subscript denotes the derivative of the function with respect to the subscript argument, evaluated at subscript $t$. It is also assumed 
that $g_{t}$ fluctuates around the trend $\left(1+\gamma_{z}\right)^{t}$.

\subsection{Functional forms and calibration}

The utility function is additive separable in logarithmic consumption and leisure, i.e., $u(c, l)=\log (c)+\psi \log (1-l)$. The production function is linear homogeneous in capital and labor i.e. $F(k, l)=k^{\theta} l^{(1-\theta)}$. The values used for the parametrization of the models are the ones taken by Chari et al. (2007), with the exception of the population growth rate which is country specific. The growth rate of labor-augmenting technical change is taken from Kehoe and Prescott (2007).

Country specific calibration of the parameters for each economy was not performed because we didn't want cross-country differences to be driven by different parametrization but rather by the distortions themselves. The values are shown in Table 1 below, at annualized rates:

Table 1: Calibration

\begin{tabular}{ccccc}
$\gamma$ & $\beta$ & $\delta$ & $\psi$ & $\theta$ \\
\hline 0.02 & 0.97 & 0.05 & 2.24 & 0.35
\end{tabular}

Given the values for the parameters in the table above, the model is solved for the steady-state quantities and the equilibrium is found. Equilibrium decision rules are derived assuming that the exogenous states (the wedges) follow a four dimensional vector auto-regressive of order one where the error process is assumed to be multivariate normal with mean zero and variancecovariance matrix $Q=B^{\prime} B$ as described below:

$$
\omega_{t+1}=P_{0}+P \omega_{t}+\epsilon_{t+1}, \epsilon \sim M V N\left(0, B^{\prime} B\right)
$$

The data is used as observables and the Kalman filter used to back out the innovations (wedges). The likelihood of the innovations being jointly normal is computed and the optimization program concerns the choice of the parameters of the VAR, i.e., the vector $P_{0}$ and the matrices $P$ and $B$, such that the likelihood is maximized. This process is repeated for each country. 
Stationarity is imposed in the estimation.

The purpose of performing simulations is to see to what extent models with just one distortion or a combination of distortions have the ability to replicate observed data. Hence, new decision rules are computed, setting the wedges, that are excluded in a specific simulation exercise, to their unconditional mean values throughout the simulation procedure. Since in they no longer are random variables in the simulations, the equilibrium decision rules and allocations in the simulated economies are consistent with the model.

\section{$3 \quad$ Wedges' trends and cycles}

The wedges are filtered using the HP-filter as in Hoddrick and Prescott (1997), with a smoothing factor of 1600. The original series, cycles and trends are presented in Appendix A. Average trends and cycles are computed by taking cross-country per quarter averages. Confidence intervals for the average trend and cycles are computed by drawing with replacement sample trend and cycles and computing their average. The empirical distribution of the average components is then used to compute the confidence intervals at the desired significance level. The shaded quarters in Figures 1 to 4 and 6, correspond to periods for which the NBER declared the U.S. economy to be in recession.

\subsection{The efficiency wedge}

The average trend for the efficiency wedge shows a modest positive slope until the early 2000's, and since then a steeper decline. For most of the sample (1975-2010), average detrended total factor productivity is significantly above one, indicating that its contribution for growth has been on average above the $2 \%$ that Kehoe and Prescott (2007) use. There is a slowdown after this period that was aggravated at the early stages of the 2008 financial crisis. The confidence intervals suggest that the series is relatively homoscedastic at the cross-sectional dimension as the amplitude remains fairly constant over the sample period. 
With respect to the cyclical component we can see that fluctuations in total factor productivity are remarkably synchronized in the sense that for many periods the fluctuations are significantly different from zero. The most notable periods of accentuated fluctuations coincide with the Yom Kippur war and the oil crisis that ensued the autumn of 1973 and the 2008 financial crisis. It is notable however that the periods the NBER declared to mark recessions in the U.S. economy coincide with the extreme realizations of the wedges, given that the data was aggregated giving equal weight to each of the 19 countries in the sample. This suggests the weight that the U.S. economy still carries in determining business cycles for the countries in the sample.

Figure 1: Average trend and cycle for the efficiency wedge
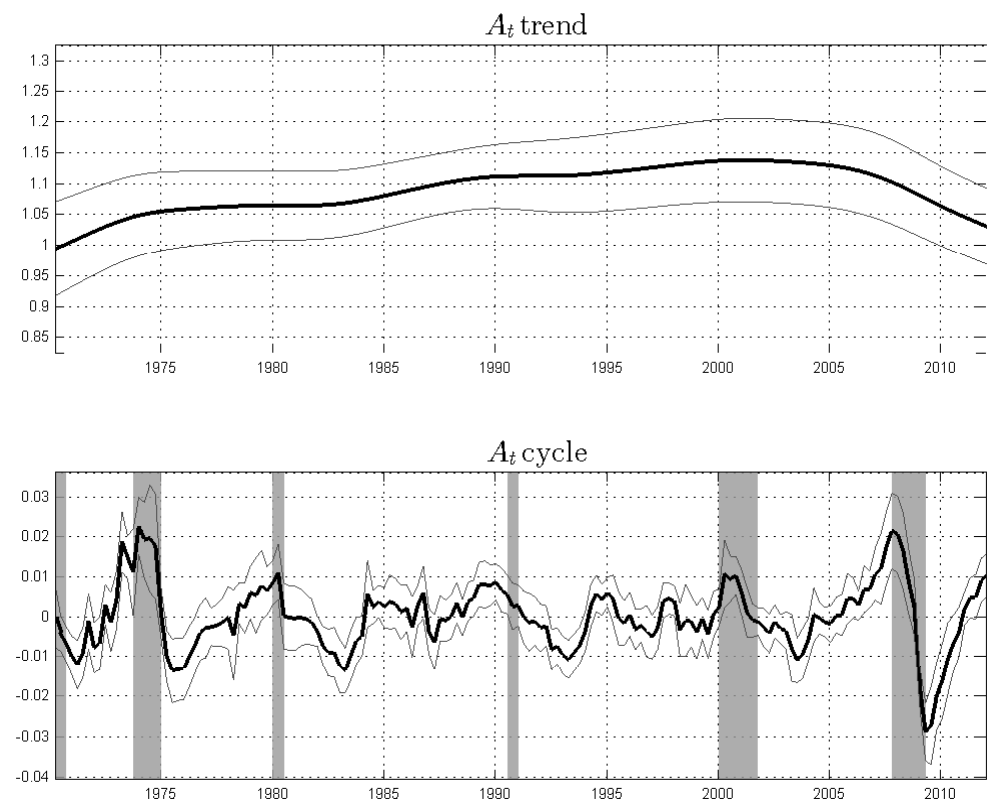

95\% Confidence intervals computed with bootstrapping, 1000 draws Shaded areas indicate U.S. recessions as declared by the NBER

\subsection{The labor wedge}

In Figure 2 we see that there is an overall tendency for the labor wedge to increase over the sample period and the increase is statistically significant. 
The average trend rose from just below 0.30 to 0.45 . As in the case for the efficiency wedge, the cross-sectional variance is fairly stable. Nonetheless there are some countries, namely the U.S. and Canada, for which the trend is downward slopping. This is also documented by Shimer (2010) and Cociuba and Ueberfedt (2010) for the U.S. economy.

Concerning the cyclical component of the labor wedge, we can see that it is also fairly synchronized over the sample period. In fact there are, as in the case for total factor productivity, many instances where the aggregate labor wedge is statistically different from zero. The cycle is also similar in amplitude to the efficiency wedge, i.e., fluctuations are of about $\pm 3 \%$. The series in itself, however, is more volatile, with more episodes comparable in magnitude to the fluctuations observed in the early 1970s and late 2000s.

Figure 2: Average trend and cycle for the labor wedge
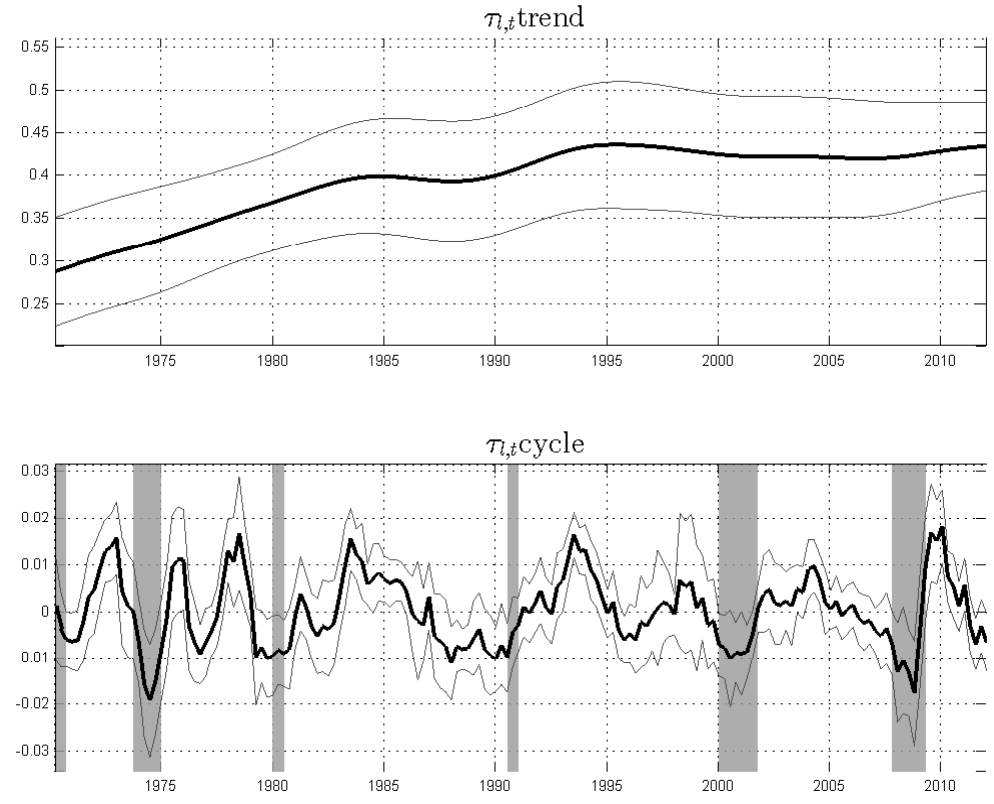

95\% Confidence intervals computed with bootstrapping, 1000 draws Shaded areas indicate U.S. recessions as declared by the NBER

As in the case of the efficiency wedge, the larger deviations from trend coincide with U.S. recessions, though where the efficiency wedge peaks at 
those, here the recessions coincide with periods for which the labor wedge is at its lowest. With regard to the U.S., Shimer (2009) finds that the cyclical component of the labor wedge rises during recessive periods. In the case for the efficiency wedge, the drop in the sample average was coincident with U.S. recessions, but in this case there seems to be a lagging effect. As can be observed in Figure 2, recessions in the U.S. coincide with local minima of the average labor wedge in our sample, and it indeed rises during, or shortly after, later periods of the recessions.

Shimer (2009) argues that two obvious explanations would be that labor and consumption taxes rise during recessions.

Note that in our prototype economy there are no consumption taxes but these would be captured by the labor wedge. To see this, notice that if the budget constraint in (2) would include taxes on consumption:

$$
\left(1+\tau_{c t}\right) c_{t}+\left(1+\tau_{x t}\right) x_{t}=\left(1-\tau_{l t}\right) w_{t} l_{t}+r_{t} k_{t}+T_{t}
$$

the labor leisure choice would then be:

$$
-\frac{u_{l t}}{u_{c t}}=\frac{1-\tau_{l t}}{1+\tau_{c t}} A_{t}(1+\gamma) F_{l t}
$$

Since the labor wedge is computed residually to make the marginal rate of substitution between labor and consumption to equate the marginal product of labor, the labor wedge reflects changes in $\frac{1-\tau_{l t}}{1+\tau_{c t}}$. Shimer (2009) cites McGrattan and Prescott (2009) in arguing that changes in consumption taxes fit the data much better than tax changes in labor income. Mertens and Ravn (2008) however, put an upper bound of $18 \%$ to the variance of output explainable by tax shocks at the business cycle frequency. As argued before, this underlines the importance of decomposing the labor wedge between trend and business cycle frequencies.

\subsection{Investment wedge}

The investment wedge, unlike with the previous two cases, exhibits much larger cross-sectional volatility. Though the point estimates in Figure 3 show 
a slight rise of the investment wedge until the late 1990s and a subsequent decline until the end of sample, the cross-sectional variance is such that we cannot reject that the average investment wedge was constant throughout our sample.

Figure 3: Average trend and cycle for the investment wedge
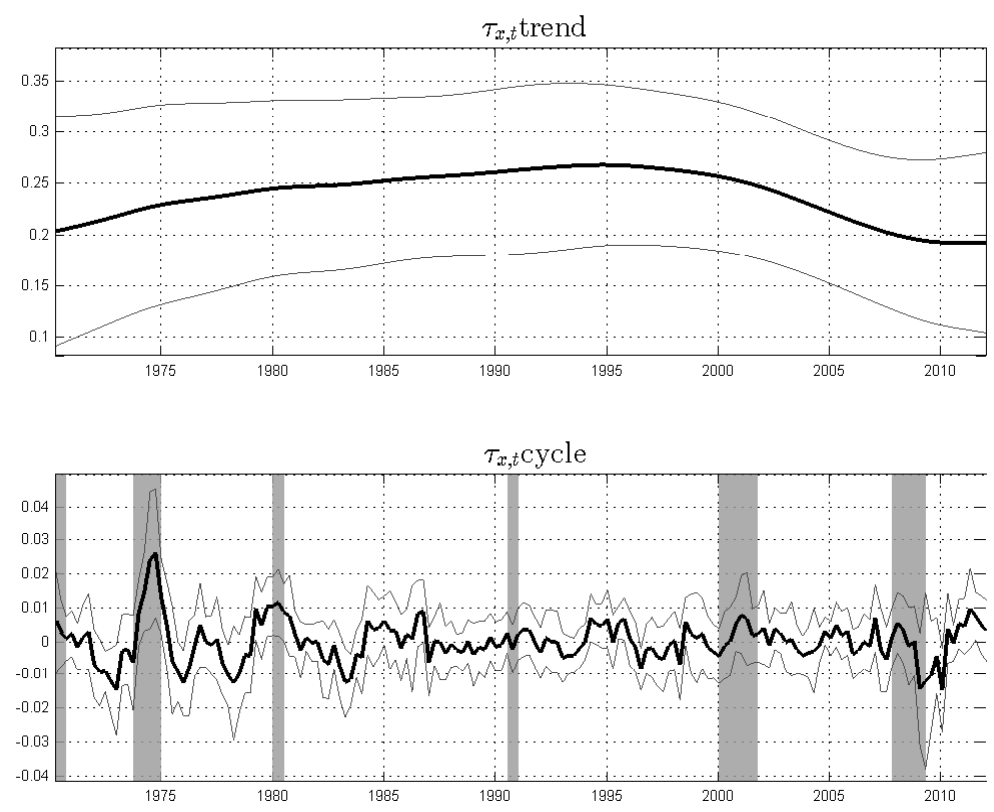

95\% Confidence intervals computed with bootstrapping, 1000 draws Shaded areas indicate U.S. Recessions as declared by the NBER

With respect to the cyclical component, both the amplitude of the deviations and the volatility are higher than in the previous two cases. Also, we find much fewer instances with statistical significance for average cyclical movements. This suggests that there is little synchronization in the sample with regard to distortions to the savings decision. Most notably, the period with the largest deviation from the trend was in the early 1970s and, unlike in the previous cases, there is hardly any co-movement with regard to the investment wedge for the last financial crisis. If we restrict ourselves though to the analysis of the point estimates, we can still partially observe the previous pattern of the wedges peaking during U.S. recessions, namely during the 
mentioned 1970's period, the 1980's slowdown and the last financial crisis.

\subsection{Government wedge}

The government wedge (government consumption plus net exports) is expressed as a fraction of output. The trend is not nearly as smooth and there is an increasing dispersion though there is a marginally significant increase in the trend component of the government wedge over the sample period.

Figure 4: Average trend and cycle for the government wedge
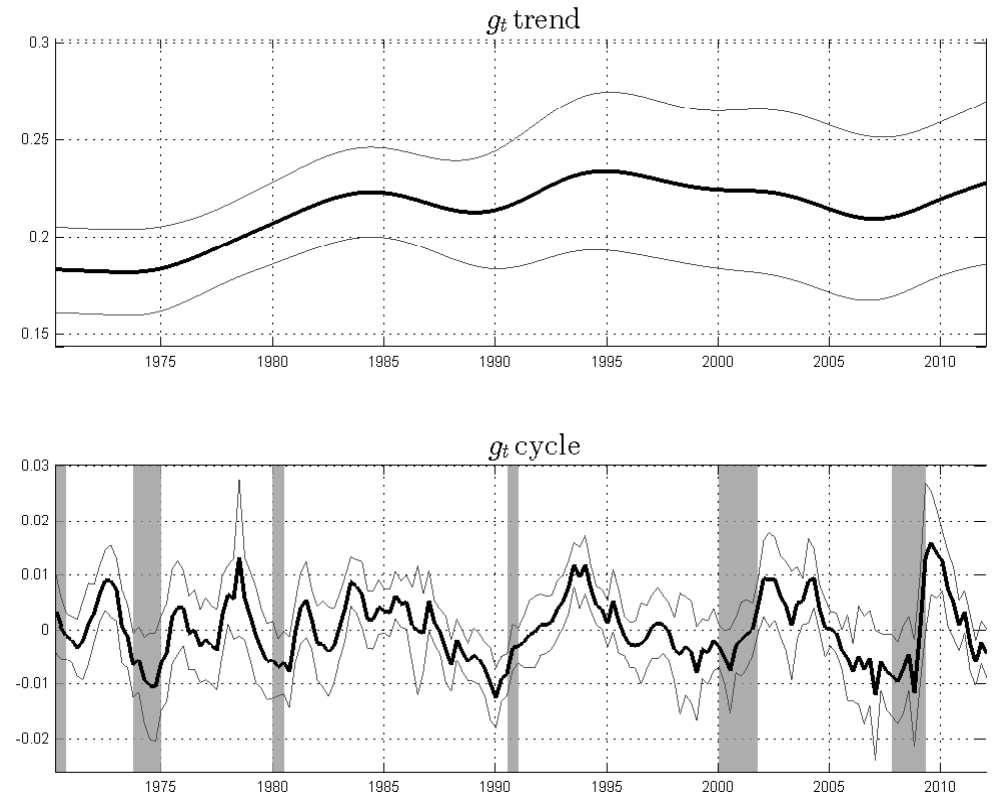

95\% Confidence intervals computed with bootstrapping, 1000 draws Shaded areas indicate U.S. recessions as declared by the NBER

With regard to the cyclical variation, as in the case for the efficiency and labor wedges, there are many instances where the average cycle is comparable in magnitude and also statistically different from zero. U.S. recessions are still a good indicator of local minima for the government wedge, though as before, there are many other instances where the deviations are statistically significant. 


\subsection{Summary statistics}

We have seen that movements in the efficiency, labor and government wedge are fairly synchronized and that have had changes in the trend component that are statistically different during several periods in the sample. The same cannot be said about the investment wedge. This indicates that there is a greater disparity in shocks to the savings decision that it is the case for the other equilibrium conditions, given the much fewer instances in which deviations from trend for the investment wedge behaved similarly enough such that they were significantly bigger(smaller) than zero.

We saw that U.S. recessions contain information regarding some features of the wedges. For example, U.S. recessions seem to lead significant drops in TFP and lead significant increases in the labor wedge. The Figure 5 below shows the lead-lag cross-correlation structure between each of the average wedges' cycles and the U.S. output cycle.

Figure 5: Lead-lag cross-correlation between $\omega_{t+j}$ and $Y_{U S, t}$
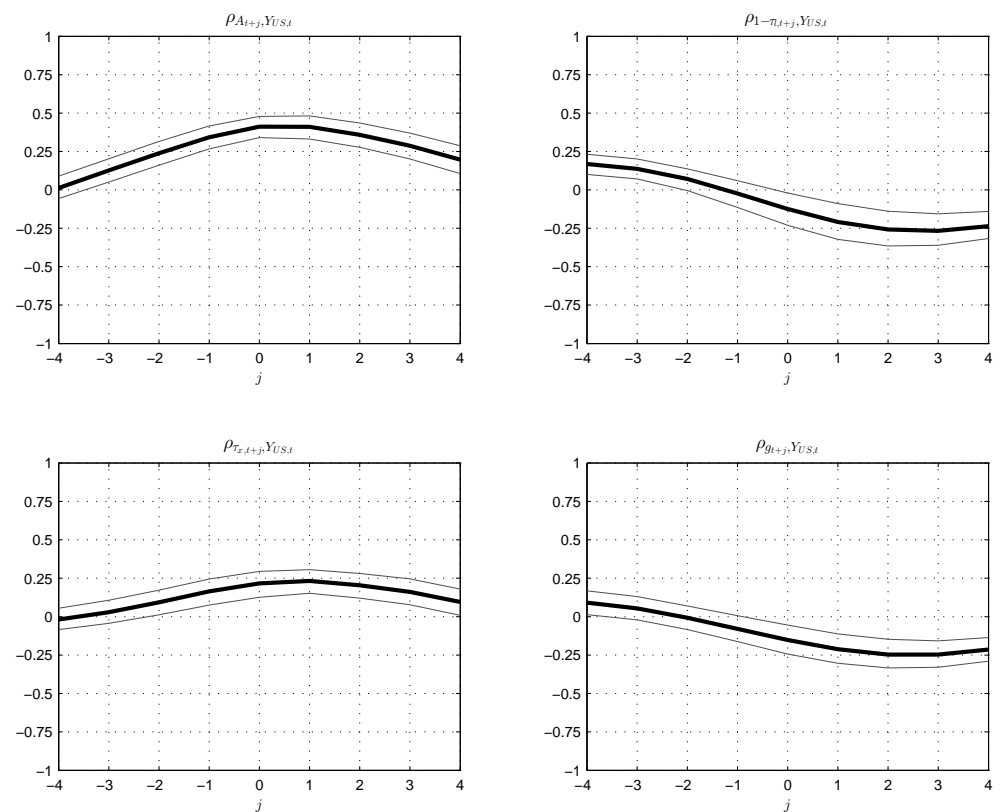

95\% Confidence intervals computed with bootstrapping, 1000 draws 
The U.S. cycle is positively correlated with TFP, with the higher point estimates suggesting it to be a coincident or leading (by one period) indicator of the rest of the sample average. With respect to the labor wedge, the contemporaneous correlation is negative, a result similar to what Shimer (2009) finds for the U.S. economy, and the estimate is statistically significant. The highest point estimate of the correlation (in absolute value) occurs with a three quarters lag making the U.S. cycle a leading indicator for the average labor wedge. The investment wedge shows a similar correlation structure as the efficiency wedge i.e. the correlation is positive and the U.S. output cycle is a coincident or leading indicator. In the case of the government wedge, the highest point estimate for the average correlation is obtained for $j=3$ and it is negative. Note that in all cases, the correlations are 'skewed to the right' i.e. the higher point estimates are mostly found for $j \geq 0$. This provides further evidence of the relevance that the U.S. cycle may have with regard to the wedges in the rest of the countries in our sample.

In Figure 6, the percentage variation explained by both the mean cycle and variance can be depicted, for each country in the sample. The total variance explained is obtained by regressing the individual series on the average components (minus the respective series) and reporting the $R^{2}$ 's of the regressions. Mean trend and cycle of the investment wedge explain less of the variation in the individual series compared to the other wedges. The average trend explains around $20 \%$ of the individual trends, against $45 \%$ for the efficiency wedge, $61 \%$ for the labor wedge and $33 \%$ of the government wedge. For the cycle, the differences are similar, with only $6 \%$ of the investment wedge cycle being explained by the average cycle against $25 \%, 15 \%$ and $13 \%$ for the efficiency, labor and government wedges respectively. This confirms our results that the investment wedge is significantly less synchronized than the other wedges, for both trend and cycle.

Another interesting aspect of Figure 6 is how France is the country whose wedges are most correlated with the average trend throughout the whole sample. With regard with the common cyclical component, France's wedges are also along the ones which show a higher degree of synchronization. A possible explanation is that out of our sample, seven countries are part of the Euro 
Area. Following Aguiar-Conraria and Soares (2011), France and Germany were found to be the core of the Euro Area i.e. the most synchronized countries with the rest of Europe. Germany is not part of the sample due to data issues $^{1}$, but the fact that France is so synchronized with the average components of the wedges lends support to previous findings from Aguiar-Conraria and Soares (2011).

Figure 6: Percentage variation explained by average trend and cycle
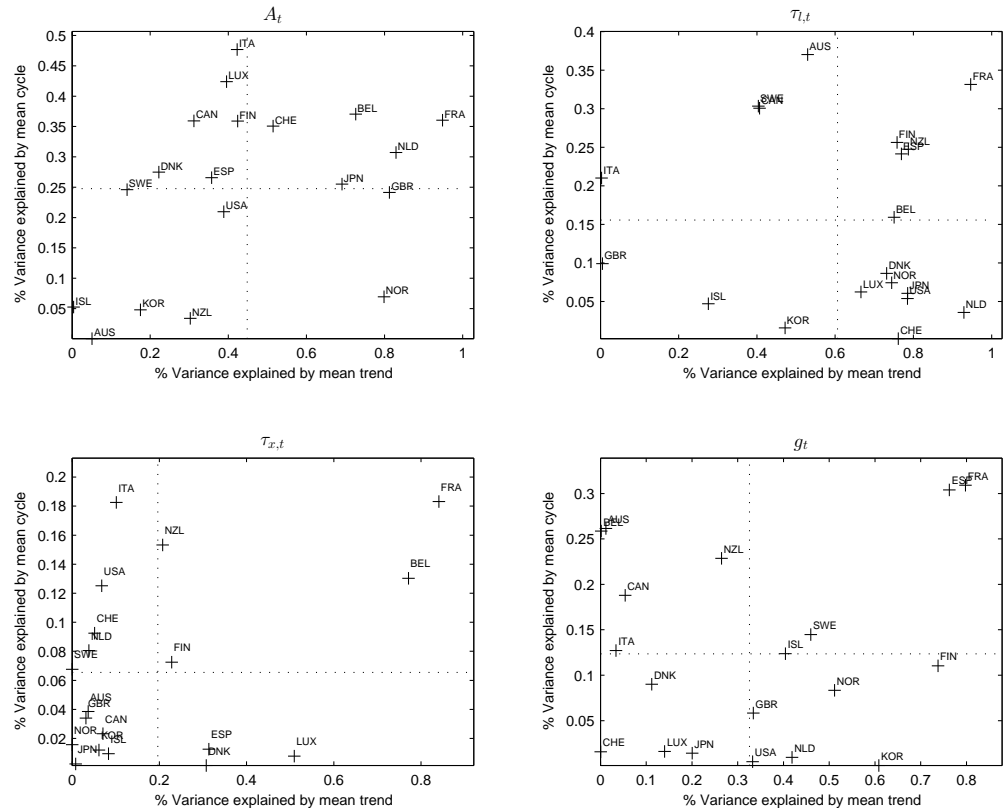

Vertical and horizontal lines concern total variance across all
series explained by average cycle and trend respectively

Figure 7 shows the cross-correlations between each of the (HP-filtered) wedges and cyclical output. The patterns of correlation between each of the wedges and cyclical output is similar enough across countries such that it allows us to draw statistical significance. The first observation is that the wedges are coincident indicators of cyclical output i.e. the absolute value of the cross-correlation reaches its highest value for the contemporaneous correlation.

\footnotetext{
${ }^{1}$ No available data on hours worked for Germany before the reunification
} 
The efficiency and investment wedges are procyclical, even though the persistence and magnitude of the procyclicality is higher in the case of the efficiency wedge. These results are in line with Chari et al. (2007). The counter-cyclicality of the government wedge is also in line with Chari et al. (2007) but not for the case of the labor wedge. In fact, for the countries and periods in the sample (and even for the U.S.), the labor wedge is countercyclical.

Figure 7: Lead-lag cross-correlation between $\omega_{t}$ and $Y_{t}+j$
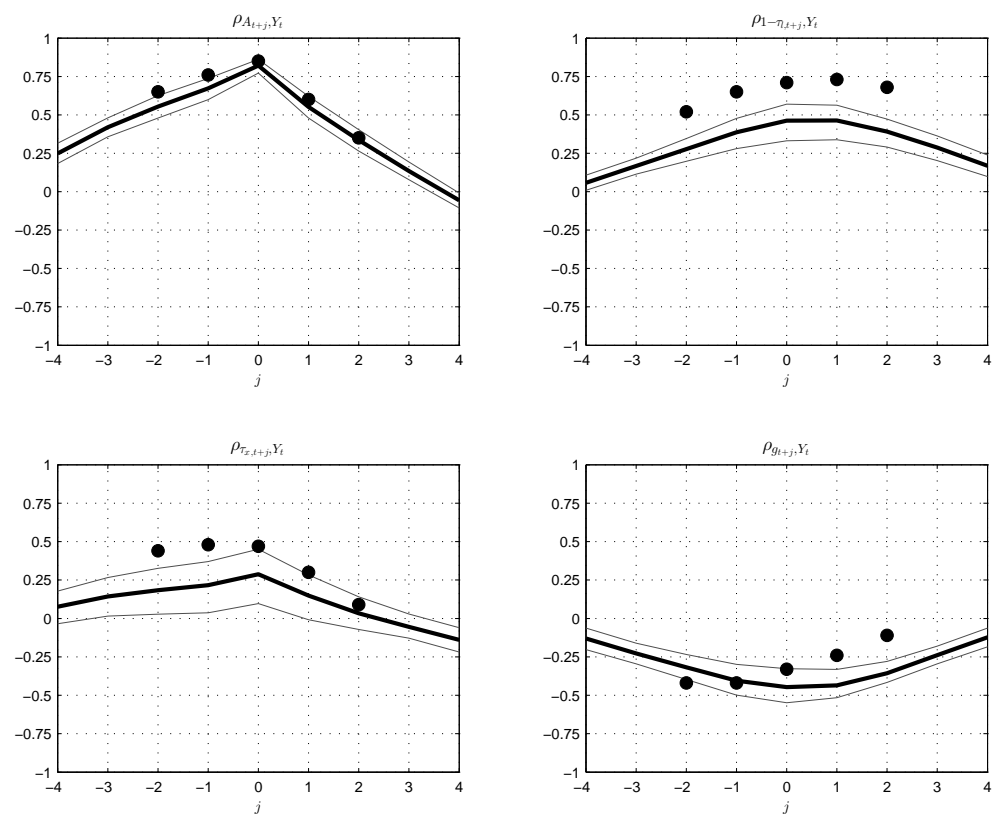

95\% Confidence intervals computed with bootstrapping, 1000 draws - - Estimates from Chari et al. (2007), for the U.S. economy

The cross-correlation structures found are similar enough across countries such that inference can be drawn at the $5 \%$ significance level, for all contemporaneous correlations and at least for one lead and lag. Comparing the results with Chari et al. (2007) with respect to the efficiency wedge, the similarity is striking. Point estimates reported in Chari et al. (2007) also show the efficiency wedge to be a coincident indicator for output. Their point estimate, 0.85 , is very similar to ours, 0.82 , and lies within our estimate's 
$95 \%$ confidence interval of $[0.77,0.87]$. With respect to the cross-correlation at different lags, we find our estimates to be of the same order of magnitude and for $j=1,2$ we can reject that they are statistically different.

When it comes to the labor wedge, our results are statistically smaller in magnitude but qualitatively in line with Chari et al. (2007). We find the average labor wedge to be procyclical on average in our sample, and this to be statistically significant for all 4 lags/leads. The only exception, i.e. a countercyclical labor wedge is the Republic of Korea. Our findings are also in line with more recent work from Shimer $(2009)^{2}$.

In the case of the investment wedge, we find it to be moderately procyclical, on average, smaller in magnitude than what Chari et al. (2007) find for the U.S. Finally, the government wedge is found to be countercyclical, though in this case our findings are much closer to what Chari et al. (2007) find for the U.S.

Another feature studied in Chari et al. (2007) concerns the relative volatility of the wedges to output. Table 2 below, presents point estimates for the average relative volatility for each of the wedges and the associated $95 \%$ confidence interval.

Table 2: Standard Deviation Relative to Output

\begin{tabular}{cccc}
$A_{t}$ & $\tau_{l, t}$ & $\tau_{x, t}$ & $g_{t}$ \\
\hline 0.89 & 1.00 & 1.12 & 0.82 \\
$(0.82,0.98)$ & $(0.89,1.14)$ & $(0.86,1.37)$ & $(0.69,0.96)$
\end{tabular}

95\% Confidence intervals computed with bootstrapping, 1000 draws

In our findings, the standard deviation of the efficiency wedge relative to that of output is found to be statistically higher than the one Chari et al. (2007) find for the U.S. (0.63). Our findings differ also in terms of the government wedge, which in our case is significantly smaller than the one found

\footnotetext{
${ }^{2}$ Notice however that Shimer (2009) results differ from ours only in the sense that the definition of labor wedge is different. We follow Chari et al. (2007) in defining the labor wedge in Figure 7 as $1-\tau_{l, t}$ for comparability. Everywhere else in the paper, the labor wedge is defined as in Shimer (2009),i.e., just $\tau_{l, t}$. As a consequence, Shimer (2009) obviously documents the labor wedge to be countercyclical instead.
} 
by the same authors (1.51). However, in the case of the labor and investment wedges, Chari et al. (2007) estimates of their relative volatility (of 0.92 and 1.18 respectively), fall within the $95 \%$ confidence interval computed for our estimates as shown in Table 2.

\section{Simulations}

Once measured the distortions, these can be considered the first best, with respect to the quantitative behavior that extensions that express themselves as distortions to the equilibrium conditions of the neoclassical growth model must exhibit. However, if the aim is to replicate movements observed in the macroeconomic aggregates, one needs also to assess the potential that the said distortions have to generate fluctuations in the data.

If we would simulate the model and feed the realizations of the four wedges as shocks i.e. the measured distortions, we would recover the original data. There is no surprise in this, since the distortions were measured precisely to make the equilibrium conditions hold with equality. However, if we do not feed all the measured wedges as shocks and simulate the model in general equilibrium allocations in the model and observed data will differ. The relevant question is then, by how much? If, for example, we model total factor productivity in such a way that we are able to exactly reproduce the efficiency wedge, how would equilibrium allocations compare with the data? Or, in a similar exercise, if we would be able to model all but one distortion in a way that would replicate exactly the measured wedges, how far could we go?

These questions are also typical applications of business cycle accounting exercises. In Chari et al. (2007), evidence points towards the efficiency and labor wedge being key margins to be modeled in order to be able to replicate movements in output, hours and investment such as the ones observed in the data for the 1981 recession and the Great Depression of 1929. Most studies seem to converge to the same conclusion. This section also adds to the literature by checking the robustness of this common finding i.e. that modeling the efficiency and labor wedges contribute to a superior performance versus 
models that aim to replicate distortions in the savings decision.

In this section we assess the performance of models with just one or with all but one wedge. First we proceed in a manner similar to the preceding section. For each country in the sample, we simulate the four observables and measure the deviations from observed data. Then we compute the cross-

Figure 8: Simulation Errors for Cyclical Output in One Wedge Economies
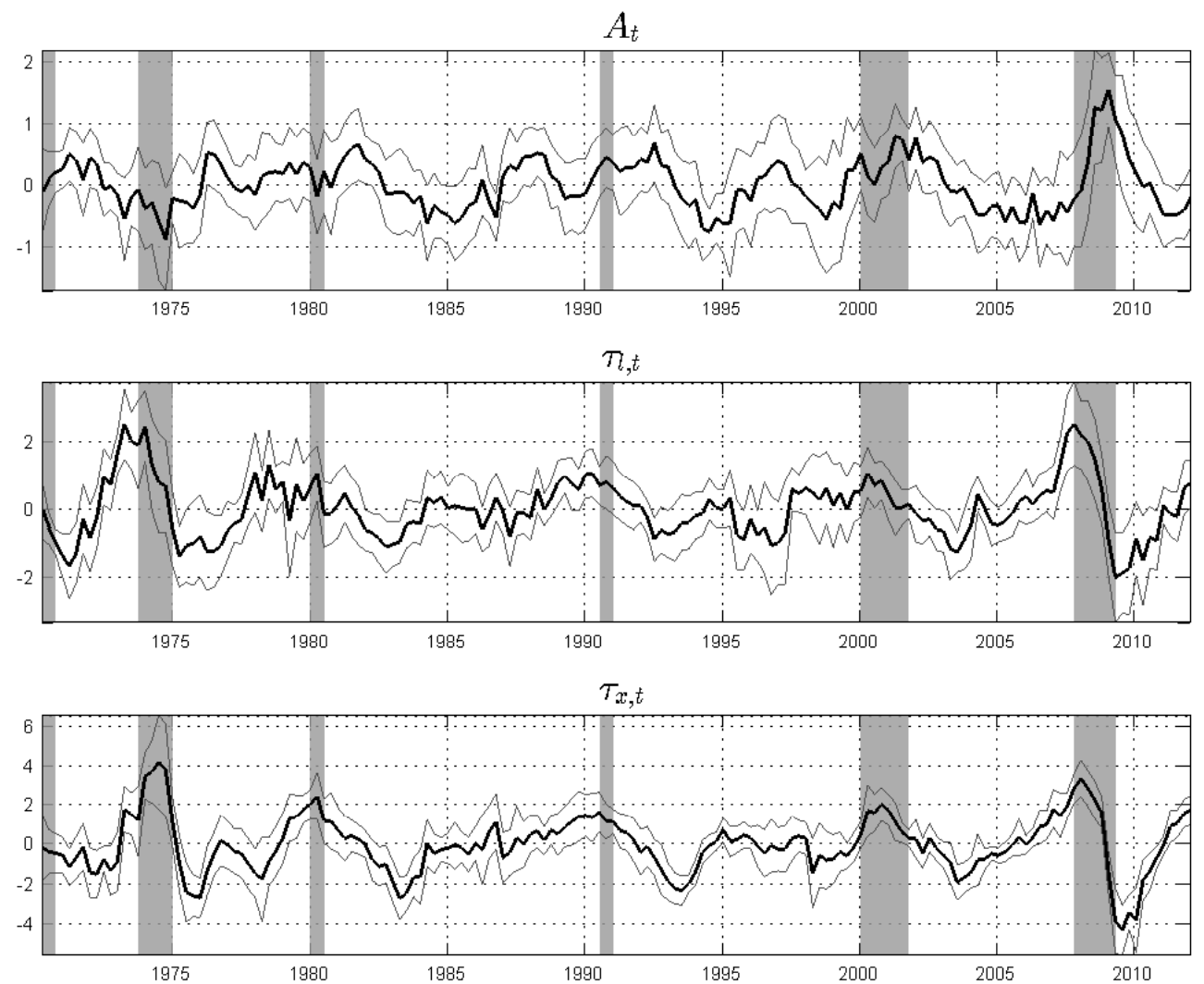

95\% Confidence intervals computed with bootstrapping, 1000 draws Shaded quarters indicate US recessions as declared by the NBER

The analysis of Figure 8 leads to several conclusions. First, economies with just the efficiency wedge have much fewer periods where the difference between observed and simulated output is similar enough across countries such that it is statistically different from zero. This only happens for 28 periods, against a total of 85 and 101 for the labor and investment wedge 
economies respectively.

Second, the efficiency wedge economies seem to produce the smaller deviations from the data, on average, followed by the labor and investment wedge economies. Third, the quarters for which simulated data more severely underestimate the magnitude of output deviations from trend coincide with recessions in the U.S. as declared by the NBER. This is even more remarkable given that the data in Figure 8 concerns (unweighted) aggregate data for the OECD countries. It seems that all models systematically underestimate the magnitude of such recessions, even though this effect is more severe in economies without the efficiency wedge. In fact, in this case, only during the 2001 and 2008 recessions, simulation errors in the efficiency wedge economy have shown to be statistically significant, where for the other three economies, this happened for all the recessions in the sample period.

Figure 9: RMSE's for Deviations from Output in One Wedge Economies

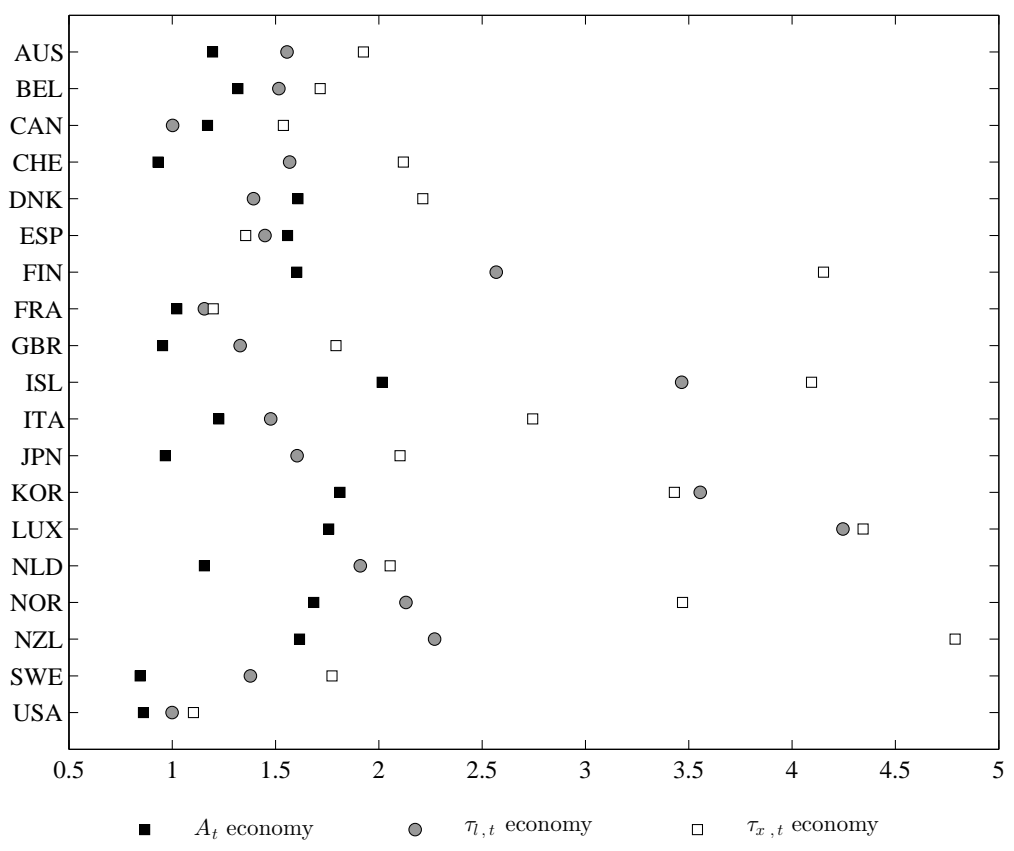

Note however, that since we are working with pooled data, smaller average deviations could just mean that the cross-sectional distribution is more symmetric. In order to check for that, Figure 9 shows the root mean square 
errors (RMSEs) for the three types of economies, in the case of deviations from output cycle. The efficiency wedge economies produce the smallest RMSEs, followed by the labor wedge and then the investment wedge economies. This ordering is observed for almost all of the countries. Also average output RMSEs are 1.33 for the efficiency wedge, 1.92 for the labor wedge and 2.52 for the investment wedge economies.

In order to have a statistical assessment of the comparative performance of the three types of models, Table 3 shows the outcome of parametric and non-parametric, joint and pairwise tests concerning the RMSEs produced. The difference between the average RMSEs between the three models is statistically significant at least at the $10 \%$ level for all comparisons.

The joint ANOVA test and its non-parametric equivalent Friedman's test both lead us to reject the null hypothesis that the average (median ranking of the) RMSEs for the three types of economies are equal.

In the first case, normality of the distribution of RMSEs is assumed and therefore the test statistic follows the $F$ distribution. In the case of Friedman's test, normality is not assumed and only the ranking of the measured RMSEs is compared between the one wedge economies, across countries. In this case, Friedman's F statistic is asymptotically $\chi^{2}$ distributed with two degrees of freedom.

Table 3: Statistical Tests of Comparative Performance

\begin{tabular}{|c|c|c|c|c|c|}
\hline Joint & p-val & Pairwise & & stat & p-val \\
\hline ANOVA & $<0.01$ & & $A_{t} \mathrm{vS} \tau_{l, t}$ & -2.62 & 0.01 \\
\hline Friedman & $<0.01$ & $t$-tests & $A_{t} \operatorname{vs} \tau_{x, t}$ & -4.27 & $<0.01$ \\
\hline Economy & RMSEs & & $\tau_{l, t}$ vs $\tau_{x, t}$ & -1.76 & 0.09 \\
\hline$A_{t}$ & 1.33 & & $A_{t} \operatorname{vs} \tau_{l, t}$ & 300.00 & 0.04 \\
\hline$\tau_{l, t}$ & 1.92 & Wilcoxon & $A_{t} \operatorname{vs} \tau_{x, t}$ & 237.00 & $<0.01$ \\
\hline$\tau_{x, t}$ & 2.52 & & $\tau_{l, t}$ Vs $\tau_{x, t}$ & 308.00 & 0.07 \\
\hline
\end{tabular}

In the case of the pairwise tests, $t$-tests were performed where the assumption is, again, that the average difference between the RMSEs is normally distributed. When using Wilcoxon's rank sum test we relax that assumption 
and take only the relative ranks into account. As in the case of the joint tests, there is no qualitative difference between the parametric and non-parametric testing if we are set to reject the null hypothesis of equal average (median ranking of the) RMSEs between the three types of economies at the $10 \%$ significance level. The finding is that, when it comes to output, the efficiency wedge is the key margin to be modeled, followed by the labor wedge and last the investment wedge.

As in Chari et al. (2007), in order to test the robustness of this finding, simulations are performed were all but one wedge are included. The equivalent to Figure 9 is reproduced in Appendix B and so is the equivalent to Table 3. The average of RMSEs for the economies with all but one wedge are of 2.04, 1.93 and 1.39 .

The economies with no efficiency wedge are the ones that perform the worst on average, followed by the economies with no labor wedge and lastly by the economies with no investment wedge, though only the comparisons of the no efficiency and no labor wedge economies against the no investment wedge economies have statistical significance.

A simple analysis of the magnitude of the RMSEs can miss an aspect that might be relevant to the researcher. A model may produce smaller RMSEs but still lead to predictions that, on average, often are more qualitatively wrong than a model that tends to produce larger RMSEs but leads to predictions that are qualitatively correct i.e. predictions that correctly indicate an expansion or contraction of output in this case.

To control for that, in Figure 10 I show the success ratios for each country's output predictions of each type of the three economies mentioned before.

The statistic in this case indicates the percentage of times that simulated and observed output are of the same sign i.e. that simulated data is below/above trend when observed data is also below/above trend.

Figure 10 is even more stark relative to previous findings. The efficiency wedge economies produce, on average, qualitatively correct predictions about $81 \%$ of the times, against $61 \%$ for the labor wedge and only $42 \%$ for the investment wedge economies.

It is worth noticing that just as the efficiency wedge economy produces 
RMSEs that are about half the size of the RMSEs associated with the investment wedge economies, the average success ratio for the efficiency wedge economy is about twice as high when compared to the same statistic regarding the investment wedge economies.

Figure 10: Success Ratios for Deviations from Output in 1 Wedge Economies

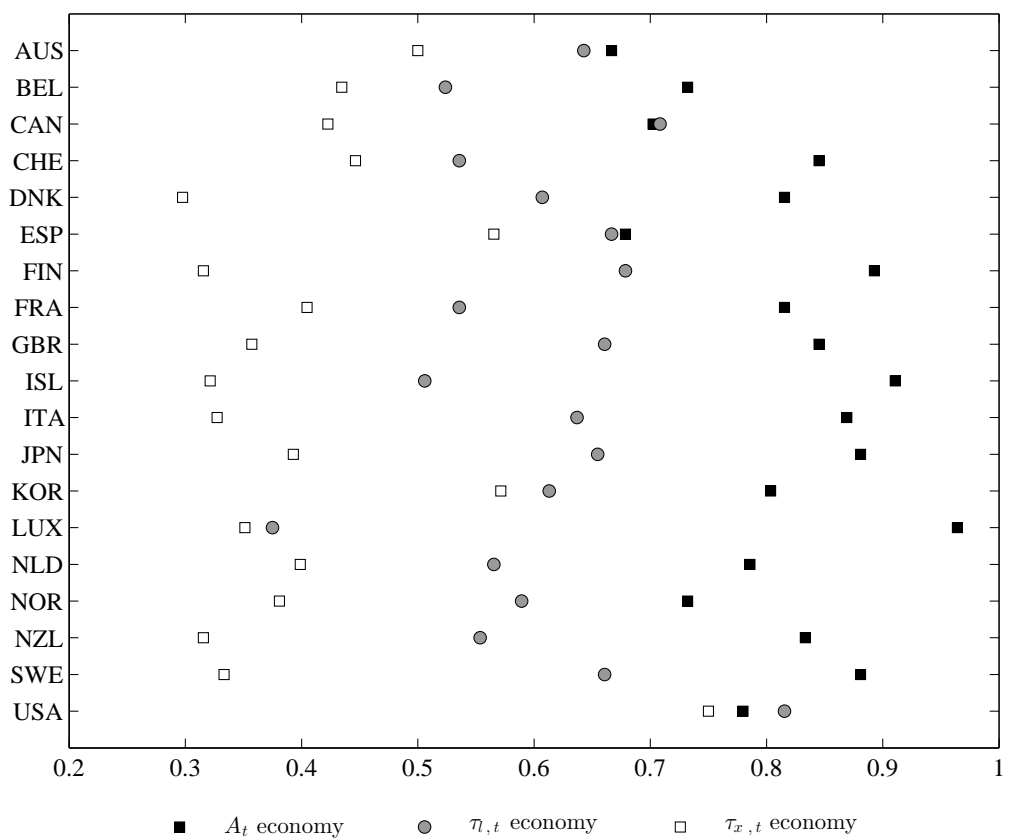

As before, statistical tests are performed and these differences are significant at the $1 \%$ level. The results also hold for all but one wedge economies, i.e., economies without the efficiency wedge have a success ratio of $51 \%$, against $73 \%$ for the no labor and $87 \%$ for the no investment wedge economies. 
Table 4: Statistical Tests of Comparative Performance

Output

\begin{tabular}{|c|c|c|c|c|c|}
\hline Joint & p-val & Pairwise & & stat & p-val \\
\hline ANOVA & $<0.01$ & & $A_{t}$ vs $\tau_{l, t}$ & 7.19 & $<0.01$ \\
\hline Friedman & $<0.01$ & $t$-tests & $A_{t} \operatorname{vs} \tau_{x, t}$ & 12.34 & $<0.01$ \\
\hline & & & $\tau_{l, t} \operatorname{vs} \tau_{x, t}$ & 5.66 & $<0.01$ \\
\hline Economy & SRs & & & & \\
\hline$A_{t}$ & $81 \%$ & & $A_{t}$ VS $\tau_{l, t}$ & 537.00 & $<0.01$ \\
\hline$\tau_{l, t}$ & $61 \%$ & Wilcoxon & $A_{t}$ vs $\tau_{x, t}$ & 546.00 & $<0.01$ \\
\hline$\tau_{x, t}$ & $42 \%$ & & $\tau_{l, t}$ VS $\tau_{x, t}$ & 511.50 & $<0.01$ \\
\hline
\end{tabular}

All this leads to the conclusion that, in terms of quantitative and qualitative relevance, the efficiency wedge is the key margin to address fluctuations in output. It is worth noting that modeling only the efficiency wedge leads to overall smaller average RMSEs than including all other wedges and leaving out the efficiency wedge, i.e., 1.33 vs 2.04 , and this result is even more clear if the success ratio is taken as measure: $81 \%$ vs $51 \%$.

The labor wedge also plays a role as it leads to better predictions concerning output than the investment wedge. This result is robust to the performance measure used (the RMSEs - 1.92 vs 2.52 or the success ratios - $61 \%$ vs $42 \%$ ) and it is statistically significant at the $10 \%$ level in the case of the labor wedge vs investment wedge economy ( $t$-statistic of -1.76 with a $p$-value of 0.09 and Wilcoxon's $p$-value of 0.07 ). In the case of the no labor wedge vs no investment wedge economy, the $t$-statistic is not significant ( $p$-value of 0.12 ) but the Wilcoxon ranksum test leads us to reject the null hypothesis at the $5 \%$ significance level. The different conclusions in the joint tests suggests that even though the ordering for each type of economies' performance (ranks) shows a statistically significant pattern $(p$-value $<0.01$ for Friedman's test), the magnitude of the differences between each type of economy for each country is quite heterogeneous, a result that can be confirmed by visual inspection of Figure 10 in Appendix B.

The investment wedge seems to be the less important margin to be mod- 
eled. It leads to higher RMSEs and lower success ratios. Also, unlike the previous two cases, economies where only the investment wedge is modeled do not even lead to predictions that are qualitatively correct $50 \%$ of the time. The average success ratio of the investment wedge economies is only of $42 \%$ and the null hypothesis of it being equal to $50 \%$ can be rejected ( $t$-statistic of -3.24 with $p$-value $<0.01$ ).

\subsection{Hours and Investment}

The above results establish the efficiency and labor wedge as key margins to be modeled in order to replicate fluctuations in output. However, the researcher maybe interested in how the different models perform with regard to replicating fluctuations in the other two observables i.e. hours worked and investment. The figures and tables shown above for output are included in Appendix B also with regard to hours worked and investment.

With regard to hours worked, the point estimates for the mean RMSEs (1.66, 1.91 and 2.33 for the efficiency, labor and investment wedge economies respectively) still single out the efficiency wedge economies in producing the smaller RMSEs on average, though there is only statistical significance when it comes to comparing the efficiency to the investment wedge economy ( $t$-statistic of -2.45 with a $p$-value of 0.02 ). When we look at the all-but-one-wedge economies, the results are different though. The no labor wedge economy is the one that produces the higher RMSEs, followed by the investment wedge and then the no efficiency wedge (1.91, 2.33 and 1.66 , respectively) and in this case, statistical significance is found for all the $t$-tests and all but one of the Wilcoxon ranksum tests. The results are shown in Appendix B, Table 2.

The labor wedge thus seems to be relatively more relevant when it comes to simulating data that resembles observed fluctuations in hours worked. This importance is even clearer if we look at the success ratios. The labor wedge economy predictions are qualitatively correct about $76 \%$ of the time, against $52 \%$ and $48 \%$ for the efficiency and investment wedge economies. The labor wedge seems key in order to make the model qualitatively in line with 
the data. This result is statistically signficant for both comparisons of the success ratios of the labor wedge with the efficiency and investment wedge economies. The results are also confirmed by the analysis of the all-but-onewedge economies, i.e., the no labor wedge economies fare comparably worse and the differences are statistically significant.

Lastly, with regard to investment, point estimates suggest the labor wedge again as being the most relevant with respect to producing the lower RMSEs on average (7.47, 9.74 and 11.80 for the labor, efficiency and investment wedge economies respectively). The all-but-one wedge economies also point in the same direction, though in both cases, there is no statistical significance. However, in terms of the success ratios, as it was the case for output, the efficiency wedge seems to matter the most and the differences are statistically significant. The efficiency wedge economy is also the only for which we can reject the null hypothesis that the success ratio (equal to 68\%) is smaller or equal to $50 \%$. As in the case of the RMSEs, this is also confirmed for the all-but-one-wedge economies.

\subsection{Summary}

The analysis of simulations for economies with just one wedge and economies with all but one wedge provide robustness to previous findings that stress the importance of modeling distortions that resemble TFP shocks in order to replicate movements in output and investment, and labor income taxes, in order to replicate movements in hours. Distortions to the savings decision, i.e., extensions that can be mapped to the investment wedge, seem of little promise both quantitatively and qualitatively.

As a final note it is worth noting that the model's ability to replicate output and hours is much higher compared with investment. As seen in Figures 1-6 in Appendix B, the average absolute simulation errors for deviations from the trend are one order of magnitude larger. This is also confirmed by the RMSEs. As an example, the RMSEs for output and hours in the efficiency wedge economy are of 1.33 and 1.66 , against 9.74 for investment. A relationship of the same magnitude can be observed for the other types of 
economies (see Tables 1-2 and Figures 7-12 in Appendix B).

\section{Structural analysis of the wedges}

The ultimate goal of a business cycle accounting exercise is to enable the reader to come forth with structural explanations for the wedges. If, for example, the the labor wedge is quantitatively relevant for a period of fluctuations, then researchers should focus in developing extensions to the prototype economy that, if mappable to the labor wedge, can replicate it. The current section contributes to the literature by bringing forth factors that contain information with respect to the said wedges.

\subsection{Spatial correlation of the wedges}

Table 5 shows that the wedges' correlations of the cyclical components across countries is correlated with the geographical distance between them (as measured by the geographical distance between each country's capital), in line with what Aguiar-Conraria and Soares (2011) find concerning business cycle synchronization in the Euro-Area.

The values correspond to Spearman's rank correlation coefficient for each of the wedges across countries (and its statistical significance). In only 11 cases out of 76 we see a positive association between the distance across two countries and the correlation coefficient between their corresponding wedges. However in all 11, these are not statistically significant. 
Table 5: Distance vs Correlation between wedges

\begin{tabular}{lllll} 
& \multicolumn{1}{c}{$A_{t}$} & $\tau_{l, t}$ & $\tau_{x, t}$ & $g_{t}$ \\
\hline AUS & $-0.42^{*}$ & -0.36 & -0.14 & -0.14 \\
BEL & $-0.56^{* *}$ & -0.38 & $-0.45^{*}$ & -0.38 \\
CAN & $-0.40^{*}$ & -0.14 & -0.14 & -0.02 \\
CHE & $-0.46^{* *}$ & -0.24 & -0.33 & -0.27 \\
DNK & $-0.49^{* *}$ & -0.22 & $-0.49^{* *}$ & -0.34 \\
ESP & $-0.51^{* *}$ & 0.02 & -0.18 & -0.06 \\
FIN & $-0.51^{* *}$ & -0.10 & -0.37 & -0.07 \\
FRA & $-0.67^{* * *}$ & -0.25 & $-0.57^{* *}$ & -0.34 \\
GBR & -0.38 & 0.11 & $-0.49^{* *}$ & -0.02 \\
ISL & $-0.44^{*}$ & 0.03 & -0.13 & -0.08 \\
ITA & $-0.79^{* * *}$ & -0.17 & $-0.47^{* *}$ & -0.24 \\
JPN & 0.08 & 0.01 & -0.38 & -0.17 \\
KOR & 0.03 & -0.24 & 0.10 & 0.00 \\
LUX & $-0.77^{* * *}$ & $-0.40^{*}$ & -0.34 & -0.31 \\
NLD & $-0.57^{* *}$ & $-0.60^{* * *}$ & -0.33 & $-0.48^{* *}$ \\
NOR & $-0.49^{* *}$ & -0.14 & -0.10 & -0.26 \\
NZL & 0.30 & -0.38 & 0.14 & -0.20 \\
SWE & $-0.75^{* * *}$ & -0.36 & $-0.48^{* *}$ & $-0.41^{*}$ \\
USA & -0.33 & -0.22 & 0.15 & -0.28 \\
\hline Statistical significance levels for Spearman's rank order correlation coefficient \\
***<0.01, ** $<0.05, *<0.10$ & &
\end{tabular}

It is thus suggested that the further two countries are apart, the lesser the wedges are correlated. This effect is especially strong in the case of the efficiency wedge, where many correlations found are indeed statistically significant at least at the $10 \%$ level.

\subsection{Degree of Openness to Trade}

The following table brings forth a second factor with potential to explain the fluctuations in the wedges at the business cycle frequency. A country's openness to trade is defined as the (HP-filtered) size of the sum of real exports and real imports as a share of real GDP.

The effect of openness in growth has been perceived in the literature as positive (Frankel and Romer (1999)). Output growth, however, can under the neoclassical model, be attributed to an increase in either capital, labor or total factor productivity. Much work has focused in the effects of trade 
openness on total factor productivity growth (see for example Abizadeh and Pandey (2009)). Typical findings are that openness indeed leads to overall TFP growth too.

Much fewer work can be found relating total factor productivity fluctuations and openness. There is extensive literature relating macroeconomic volatility in general, or output growth volatility in particular, to openness. There is an ongoing debate regarding its effects but it also focuses more on developing countries (see Haddad et al. (2012) for example), whereas our sample consists of a subset of OECD countries.

In earlier work, Easterly et al. (2001) report a per capita GDP growth volatility correlation with our measure of openness of 0.00013 ( $t$-statistic of 2.043) for the overall sample but found OECD countries to show overall less GDP growth volatility (average growth volatility to be -0.03515 smaller than the sample average, with a $t$-statistic of -4.44 ).

In Table 6 we provide evidence on the information that our measure of openness contains with regard to the measured wedges. With regard to TFP or the efficiency wedge, in 15 out of 19 countries, the correlations are significant at least at the $5 \%$ level. In all of those 15 cases, the correlation is positive.

With regard to the labor wedge, all significant (at least at the 10\% level) correlations are negative, except one - Luxembourg. As in the case before, this happens for 15 out of the 19 countries in the sample.

For the investment wedge, fewer correlations (14) are found to be statistically significant and 11 to be positive. Finally for the government wedge, 13 correlations are found to be significant (at least at the $5 \%$ level) and all but one - again, Luxembourg - to be negative. 
Table 6: Trade openness correlation with the wedges

\begin{tabular}{lcccc} 
& $A_{t}$ & \multicolumn{1}{c}{$\tau_{l, t}$} & $\tau_{x, t}$ & $g_{t}$ \\
\hline AUS & 0.02 & $-0.41^{* * *}$ & 0.10 & $-0.43^{* * *}$ \\
BEL & $0.61^{* * *}$ & $-0.41^{* * *}$ & $0.67^{* * *}$ & $-0.46^{* * *}$ \\
CAN & $0.63^{* * *}$ & $-0.56^{* * *}$ & $0.30^{* * *}$ & $-0.46^{* * *}$ \\
CHE & $0.49^{* * *}$ & 0.02 & $0.22^{* * *}$ & 0.00 \\
DNK & -0.06 & $-0.15^{*}$ & $0.14^{*}$ & -0.02 \\
ESP & $0.36^{* * *}$ & $-0.47^{* * *}$ & 0.02 & $-0.57^{* * *}$ \\
FIN & $0.52^{* * *}$ & -0.07 & $0.29^{* * *}$ & 0.05 \\
FRA & $0.61^{* * *}$ & $-0.44^{* * *}$ & $0.50^{* * *}$ & $-0.60^{* * *}$ \\
GBR & $0.20^{* * *}$ & $-0.30^{* * *}$ & $0.20^{* * *}$ & $-0.27^{* * *}$ \\
ISL & $0.18^{* *}$ & $-0.25^{* * *}$ & $-0.14^{*}$ & $-0.42^{* * *}$ \\
ITA & $0.62^{* * *}$ & -0.04 & $0.23^{* * *}$ & -0.12 \\
JPN & $0.38^{* * *}$ & $-0.21^{* * *}$ & $0.14^{*}$ & 0.01 \\
KOR & $0.37^{* * *}$ & $-0.26^{* * *}$ & $-0.28^{* * *}$ & $-0.27^{* * *}$ \\
LUX & $0.32^{* * *}$ & $0.23^{* * *}$ & 0.07 & $0.19^{* *}$ \\
NLD & $0.38^{* * *}$ & -0.07 & $0.20^{* * *}$ & -0.09 \\
NOR & 0.03 & $-0.17^{* *}$ & 0.11 & $-0.21^{* * *}$ \\
NZL & -0.10 & $-0.33^{* * *}$ & 0.04 & $-0.36^{* * *}$ \\
SWE & $0.45^{* * *}$ & $-0.24^{* * *}$ & $0.19^{* *}$ & $-0.22^{* * *}$ \\
USA & $0.44^{* * *}$ & $-0.67^{* * *}$ & $-0.51^{* * *}$ & $-0.50^{* * *}$ \\
\hline
\end{tabular}

Statistical significance levels for Spearman's rank order correlation coefficient $* * *<0.01,{ }^{* *}<0.05, *<0.10$

\section{Conclusion}

This paper studies the properties of distortions to the neoclassical growth model that manifest themselves as shocks to productivity, labor income taxes, investment taxes, and government consumption. It is shown that deviations from the trend with regard to these distortions are relatively more synchronized in the case of the efficiency, labor and government wedge than in the case of the investment wedge. Recessions in the U.S. typically coincide with local extreme points in the wedges for the aggregate data and these movements are similar enough to be statistically significant in the case of the efficiency, labor and government wedges. This is even more remarkable given that the data used is unweighted and shows the impact the U.S. hold for business cycle fluctuations for the rest of the OECD countries in the sample.

Our simulations show that the efficiency wedge is paramount in providing 
models the ability to replicate movements in output and investment. With regard to output, an economy with just an efficiency wedge outperforms, on average, an economy with all the other three wedges. The labor wedge is also of relevance in replicating movements in hours and investment where the investment wedge holds little to no qualitative or quantitative importance. These conclusions are statistically significant for the countries in the sample and do not limit themselves to periods such as output drops, as it has been traditionally done in the literature.

The original findings of Chari et al. (2007) with respect to the irrelevance of the investment wedge are therefore reinforced by these results and are also valid for business cycle fluctuations in general. However, how to reconcile the general notion that many of the recent recessions were due to failures of the financial system with such irrelevance? One should draw attention to the fact that the financial system has two purposes. First it allows the allocation of resources across time and states of the world. It allows consumers to smooth their consumption in a context of variable income, or firms to stabilize their liquidity in face of revenue/cost shocks. The second function is to channel savings to their most productive uses. The first purpose is reflected in the model by the Euler equation and its associated wedge is precisely the investment wedge. The second function of the financial markets is captured by the efficiency wedge. As mentioned before, Chari et al. (2007) describe a detailed two sectors economy with different costs of borrowing. In this case, they derive an equivalence theorem between the detailed economy and a prototype economy with an efficiency wedge.

The conclusion here is that promising theories of financial crisis should focus on the role of the financial system in channeling savings to their most efficient uses, and less so in its role of allocating resources across time. The issue of liquidity crisis is not persistent enough across time, and especially hard to capture at the quarterly frequency even in studies of financial crisis which has been typically the aim of much of the literature. An exception is precisely Dooyeon and Doblas-Madrid (2012) that find some relevance of the investment wedge for a selected sample of east Asian economies, but again, limited to financial crisis. In a context of distortions that aim to generate 
fluctuations in aggregates that are not limited to output drops or crisis, the relevance of such channel is expected to be even less important.

Also, we show that the per type of wedge across country correlation is negatively correlated with the distance between the countries, even though only for the efficiency wedge we can find strong statistical significance. As mentioned before, this type of analysis is common in the trade literature, where trade volumes are often (also) explained by gravitation equations. The degree of openness to trade of a country is also found to contain significant information with regard to all four wedges which reinforces the role of international mechanisms of transmission for distortions in the key margins of the neoclassical growth model.

Further analysis should focus in finding more factors that contain information with regard to these distortions, so that we can provide business cycle theorists hints of mechanisms that hold promise in generating fluctuations as observed in the data. 


\section{References}

Abizadeh, S. and Pandey, M. (2009). Trade openness, structural change and total factor productivity. International Economic Journal, 23(4):545-559.

Aguiar-Conraria, L. and Soares, M. J. (2011). Business cycle synchronization and the Euro: A wavelet analysis. Journal of Macroeconomics, 33:477-489.

Bernanke, B. M., Gertler, M., and Gilcrhist, S. (1999). The financial accelerator in a quantitative business cycle framework. Handbook of Macroeconomics, 1C:1341-1393.

Calstrom, C. T. and Fuerst, T. S. (1997). Agency costs, net worth and business cycle fluctuations: a computable general equilibrium analysis. American Economic Review, 87:893-910.

Chari, V., Kehoe, P., and McGrattan, E. (2007). Business cycle accounting. Econometrica, 75:781-836.

Cociuba, S. E. and Ueberfedt, A. A. (2010). Trends in U.S. hours and the labor wedge. Bank of Canada Working Paper Series, (28).

Dooyeon, C. and Doblas-Madrid, A. (2012). Business cycle accounting east and west: Asian finance and the investment wedge. Review of Economic Dynamics. Available online 17 October 2012, ISSN 1094-2025, 10.1016/j.red.2012.10.003.

Easterly, W., Islam, R., and Stiglitz, J. E. (2001). Shaken and stirred: explaining growth volatility. In Annual World Bank conference on development economics, volume 191, page 211.

Frankel, J. A. and Romer, D. (1999). Does trade cause growth? American economic review, pages 379-399.

Haddad, M., Lim, J. J., Pancaro, C., and Saborowski, C. (2012). Trade openness reduces growth volatility when countries are well diversified. $E C B$ Working Paper. 
Hoddrick, R. and Prescott, E. (1997). Post-war U.S. business cycles: an empirical investigation. Journal of Money, Credit and Banking, 29:1-16.

Islam, N., Dai, E., and Sakamoto, H. (2006). Role of TFP in China's growth. Asian Economic Journal, 20(2):127-156.

Kehoe, T. J. and Prescott, E. C. (2007). Great depressions of the twentieth century. Federal Reserve Bank of Minneapolis.

Kobayashi, K. and Inaba, M. (2006). Business cycle accounting for the Japanese economy. RETI Discussion Paper, 05-E-023.

Kydland, F. E. and Prescott, E. C. (1982). Time to build and aggregate fluctuations. Econometrica, 50(6):1345-70.

Lamas, R. (2009). Accounting for output drops in Latin America. IMF Working Paper Series, 67.

McGrattan, E. R. and Prescott, E. C. (2009). Technical appendix: Unmeasured investment and the puzzling US boom in the 1990 s.

Mertens, K. and Ravn, M. (2008). The aggregate effects of anticipated and unanticipated us tax policy shocks: Theory and empirical evidence. CEPR Discussion Paper No. DP6673.

Mulligan, C. B. (2002). A century of labor-leisure distortions. NBER Working Papers, (8774).

Otsu, K. (2009). International business cycle accounting. IMES Discussion Paper Series, 29.

Restrepo-Echavarria, P. and Cheremukhin, A. A. (2010). The labor wedge as a matching friction. Federal Reserve Bank of Dallas Working Paper Series, (1004).

Shimer, R. (2009). Convergence in macroeconomics: The labor wedge. American Economic Journal: Macroeconomics, 1(1):280-97. 
Shimer, R. (2010). Labor Markets and Business Cycles. Princeton University Press.

Simonovska, I. and Söderling, L. (2008). Business cycle accounting for Chile. IMF Working Paper Series, 61.

Solow, R. M. (1957). Technical change and the aggregate production function. The Review of Economics and Statistics, 39(3):312-320.

Sustek, R. (2010). Monetary business cycle accounting. Review of Economic Dynamics, 14(4):592-612. 
Appendix A - Country Profiles 


\section{Australia}
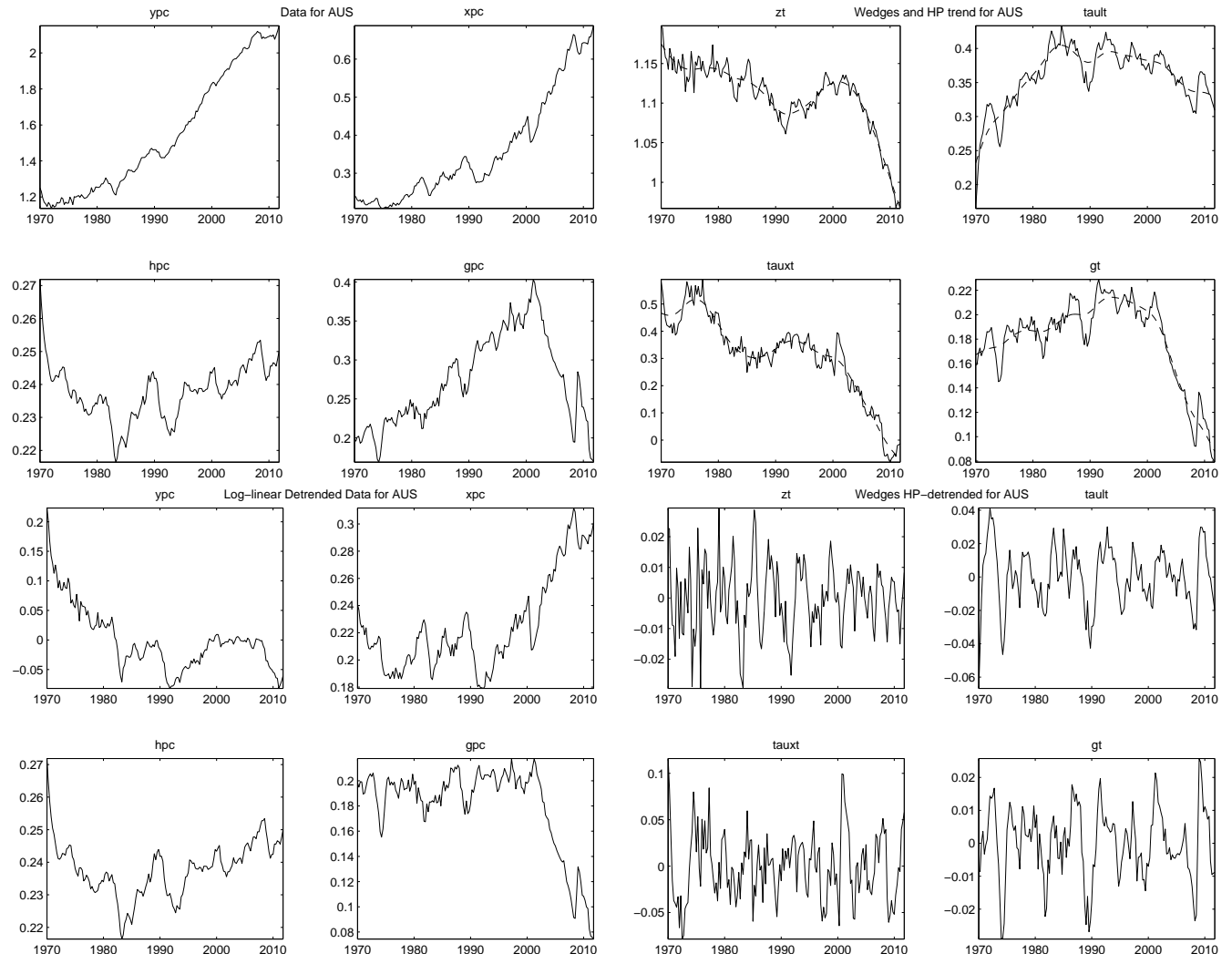

\section{Belgium}
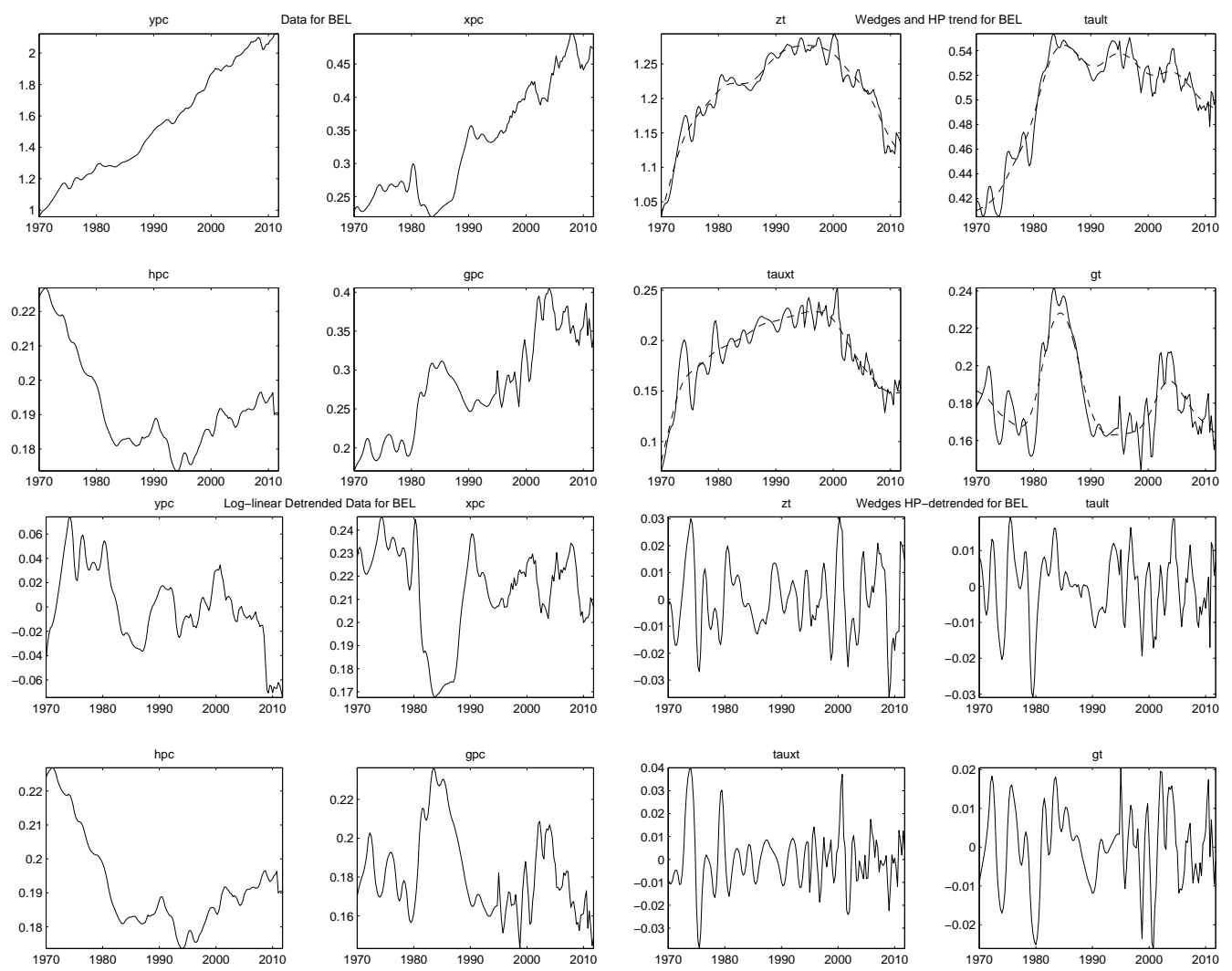


\section{Canada}
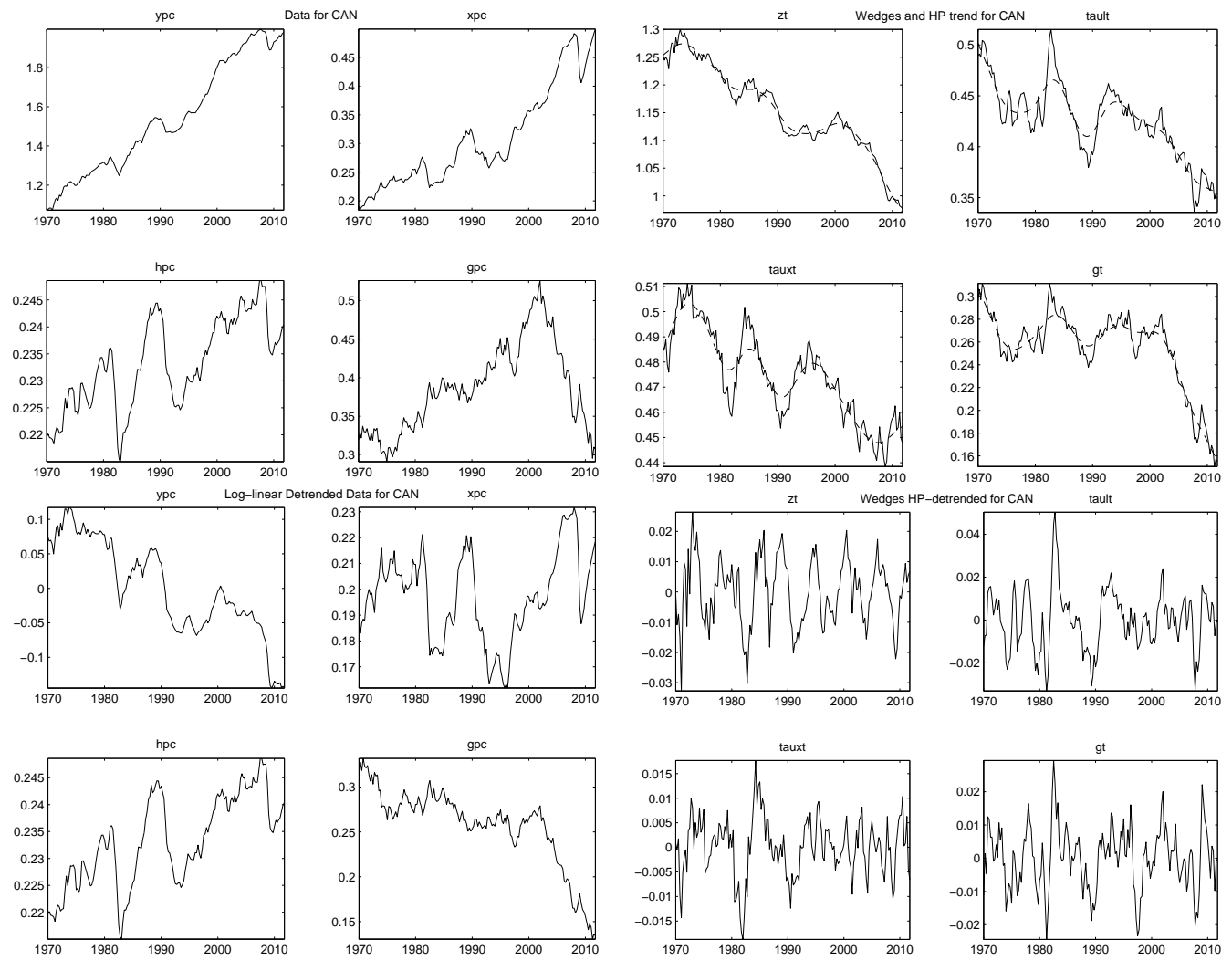

\section{Swtizerland}
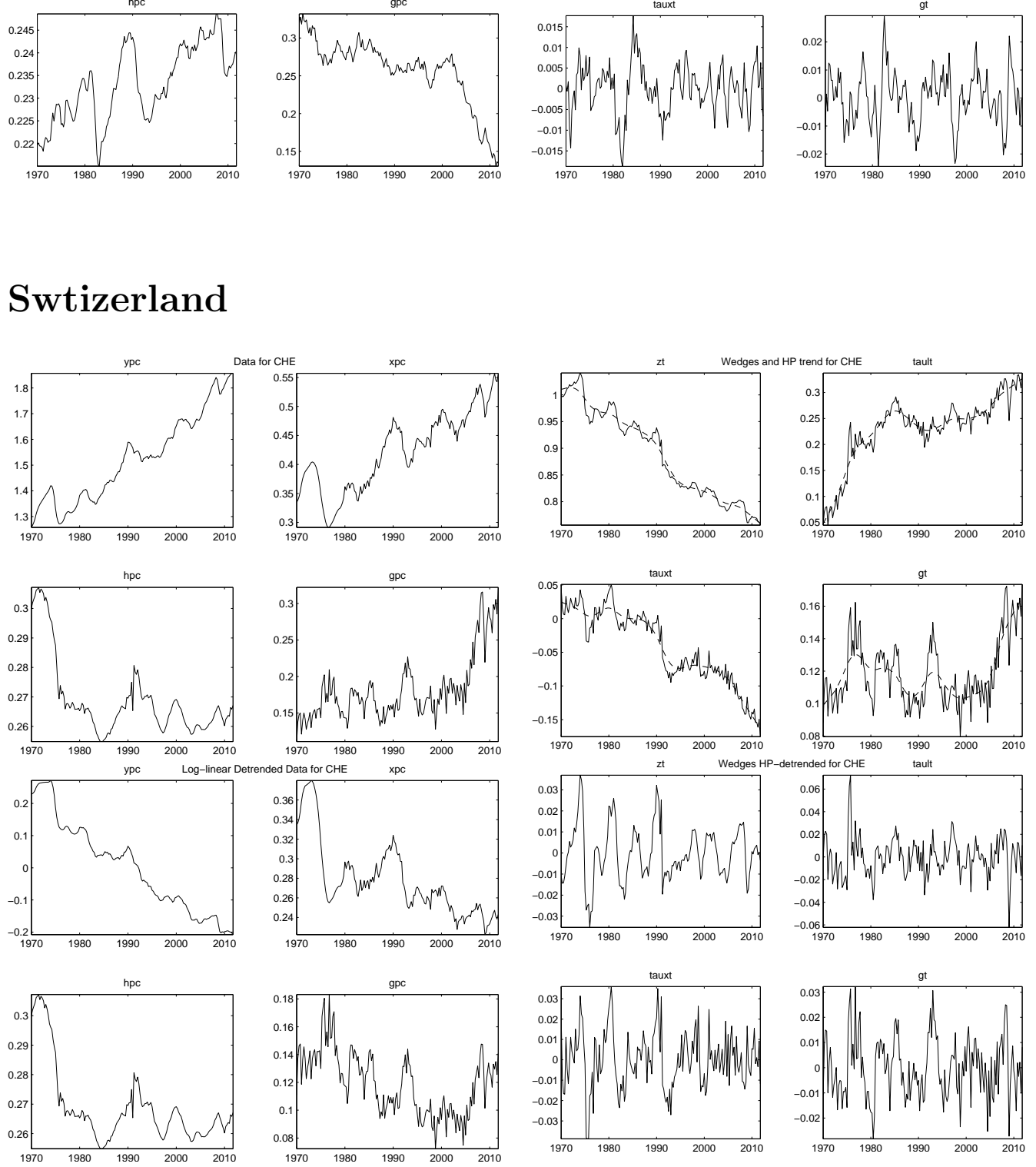


\section{Denmark}
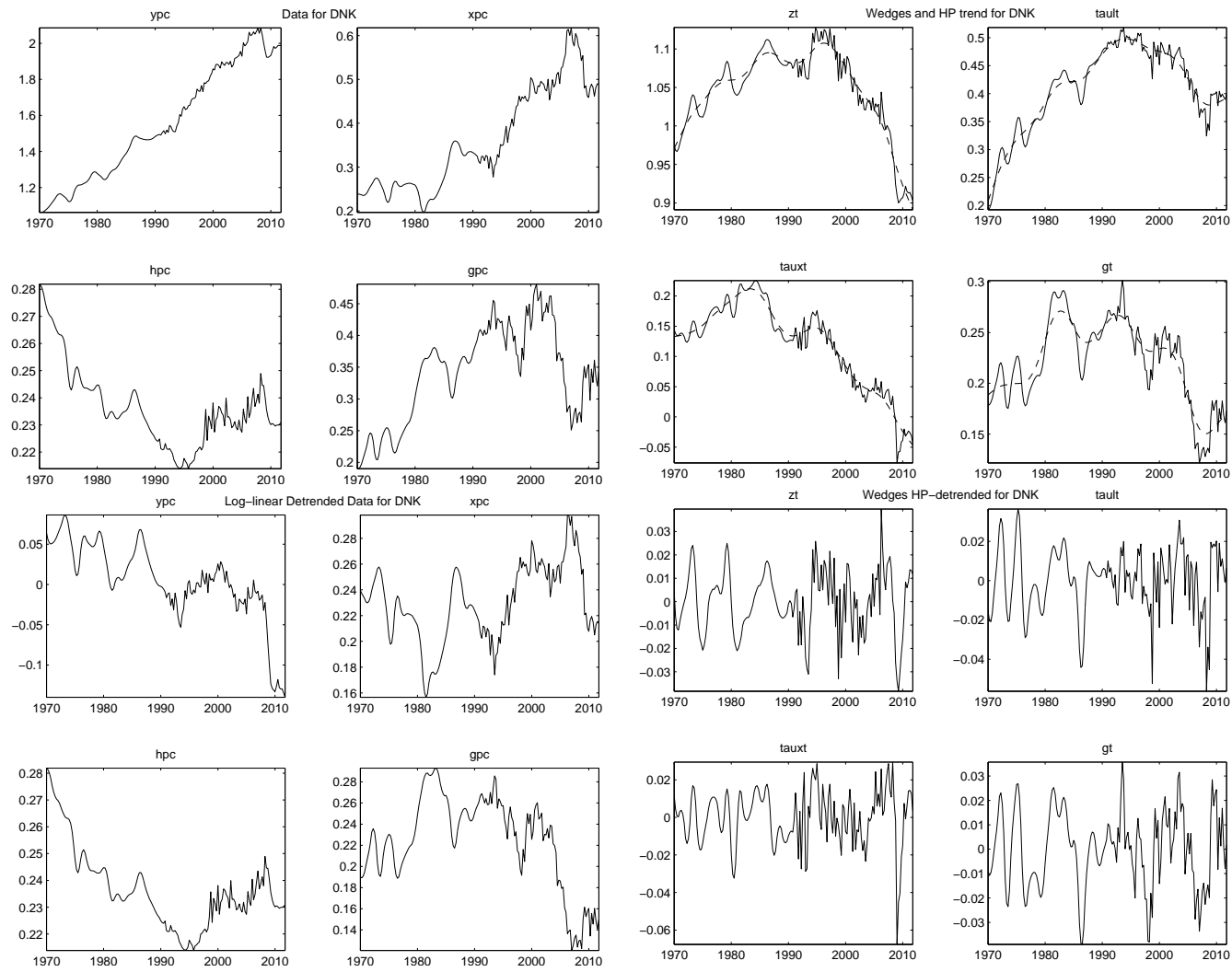

\section{Spain}
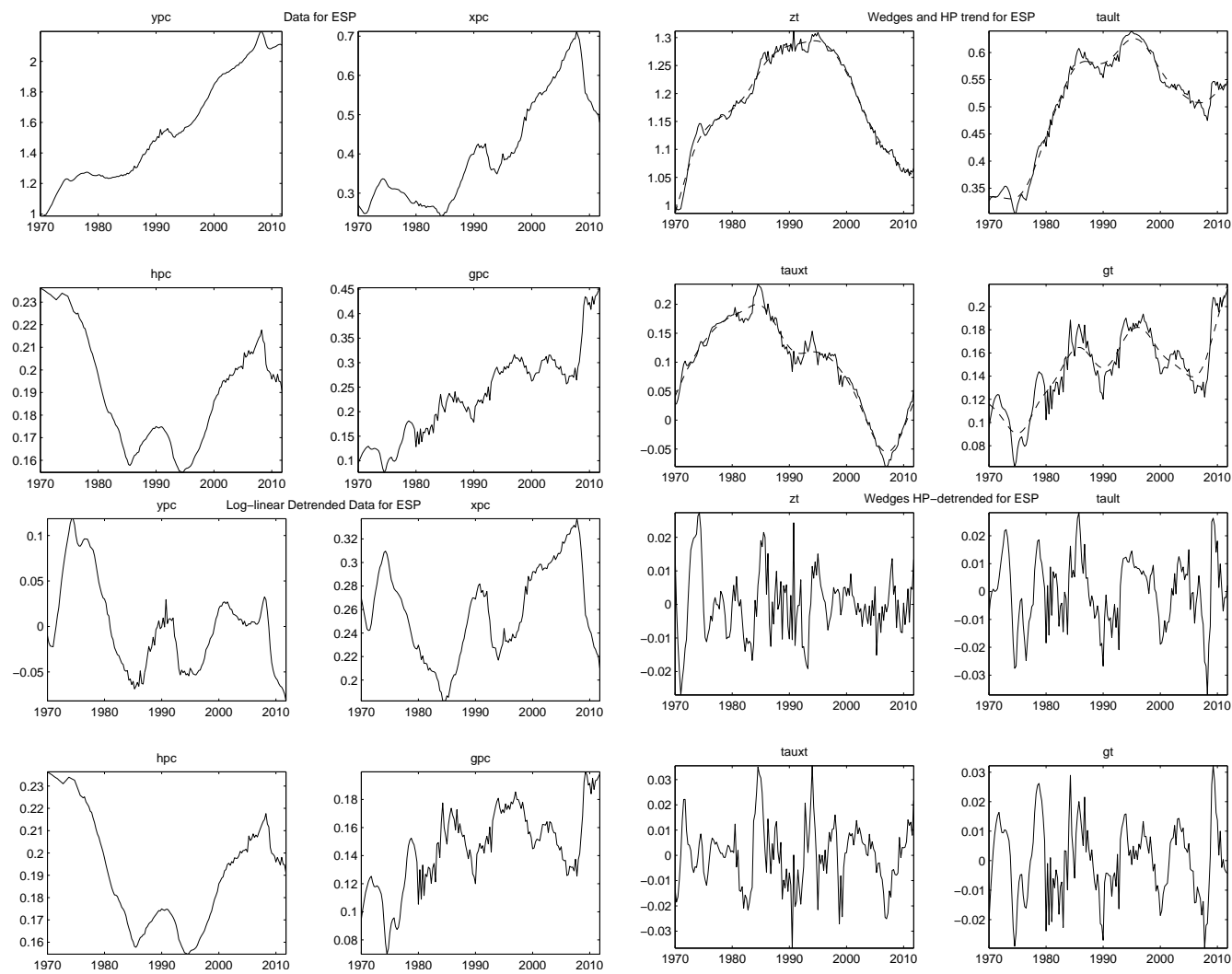


\section{Finland}
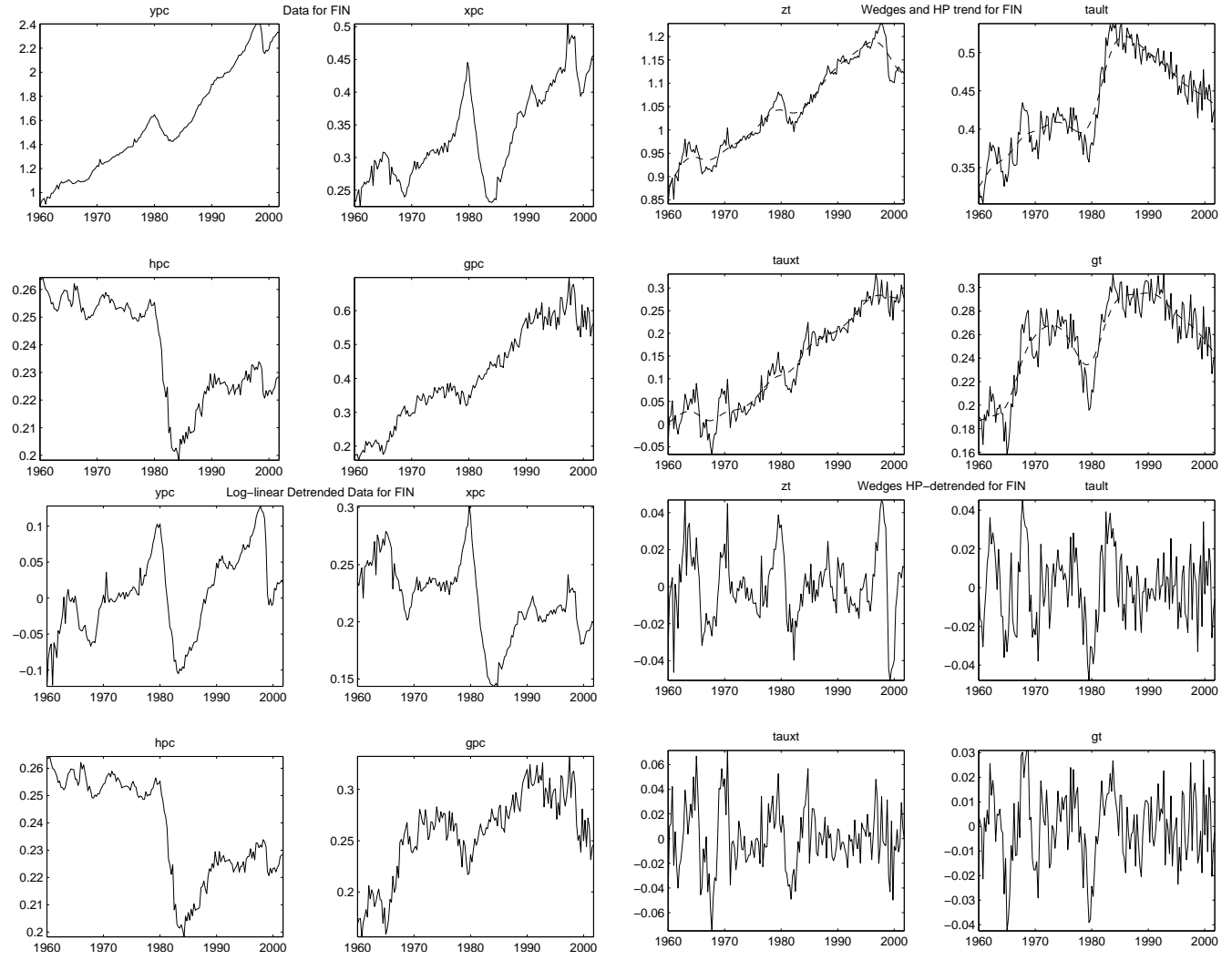

\section{France}
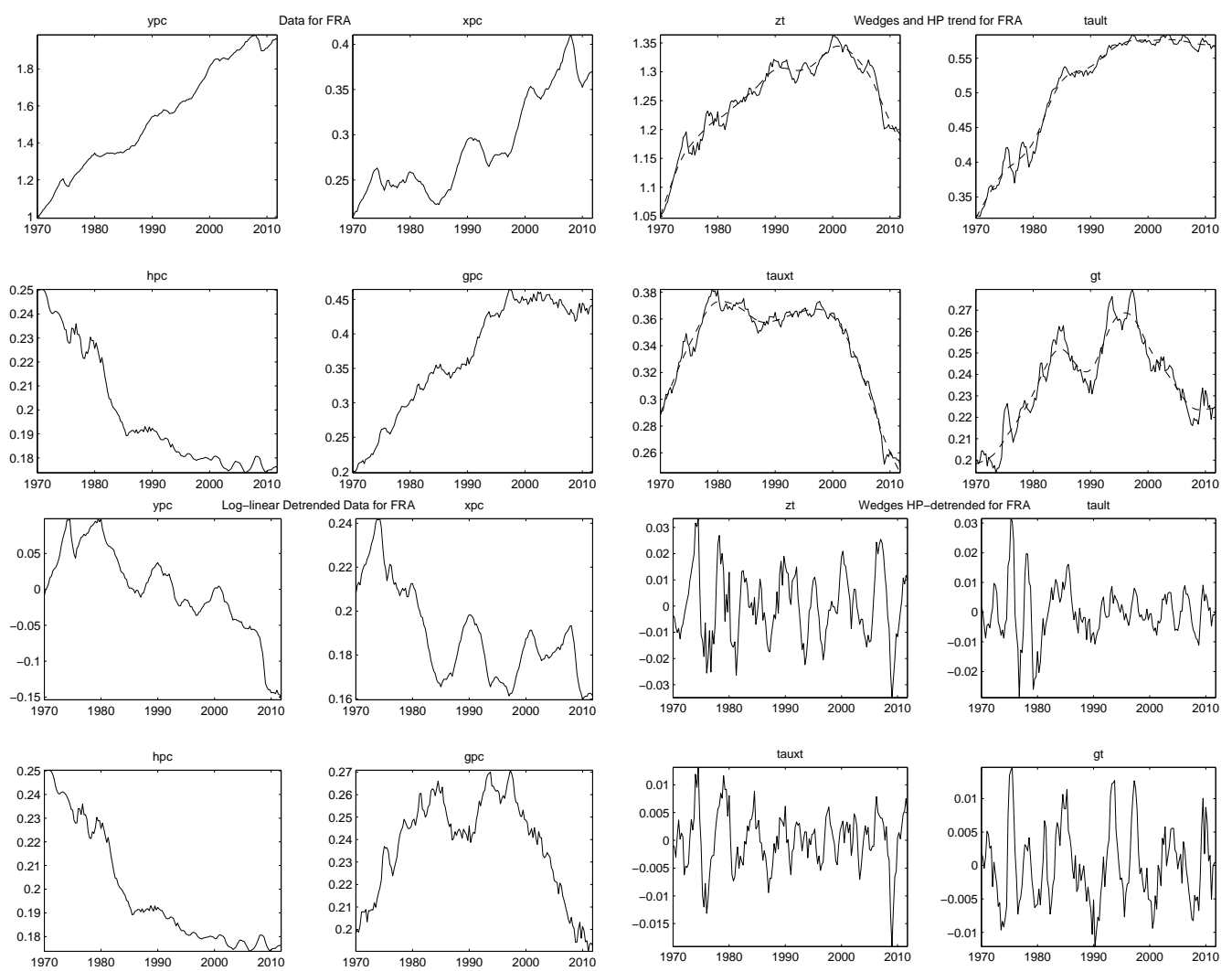


\section{Great Britain}
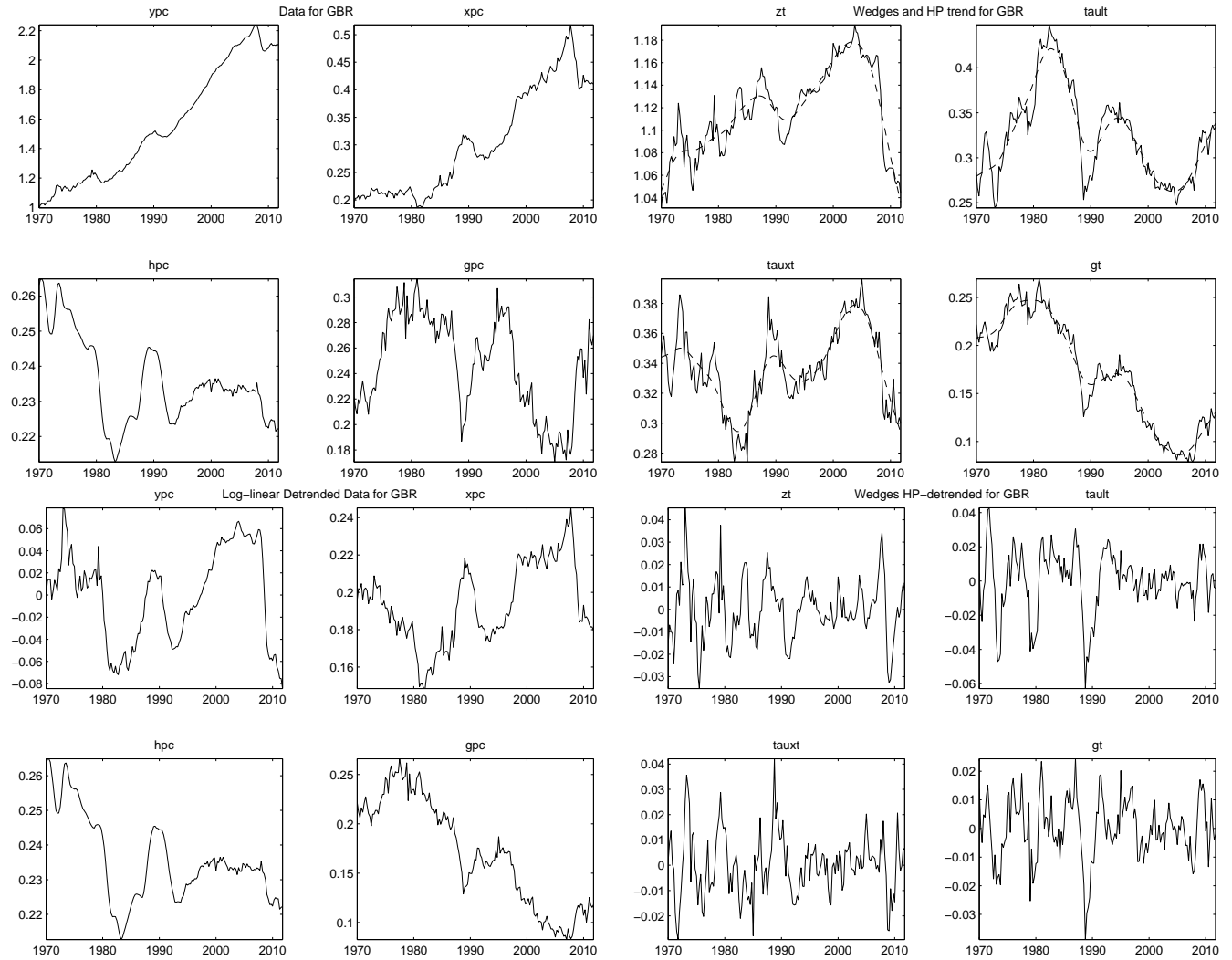

\section{Iceland}
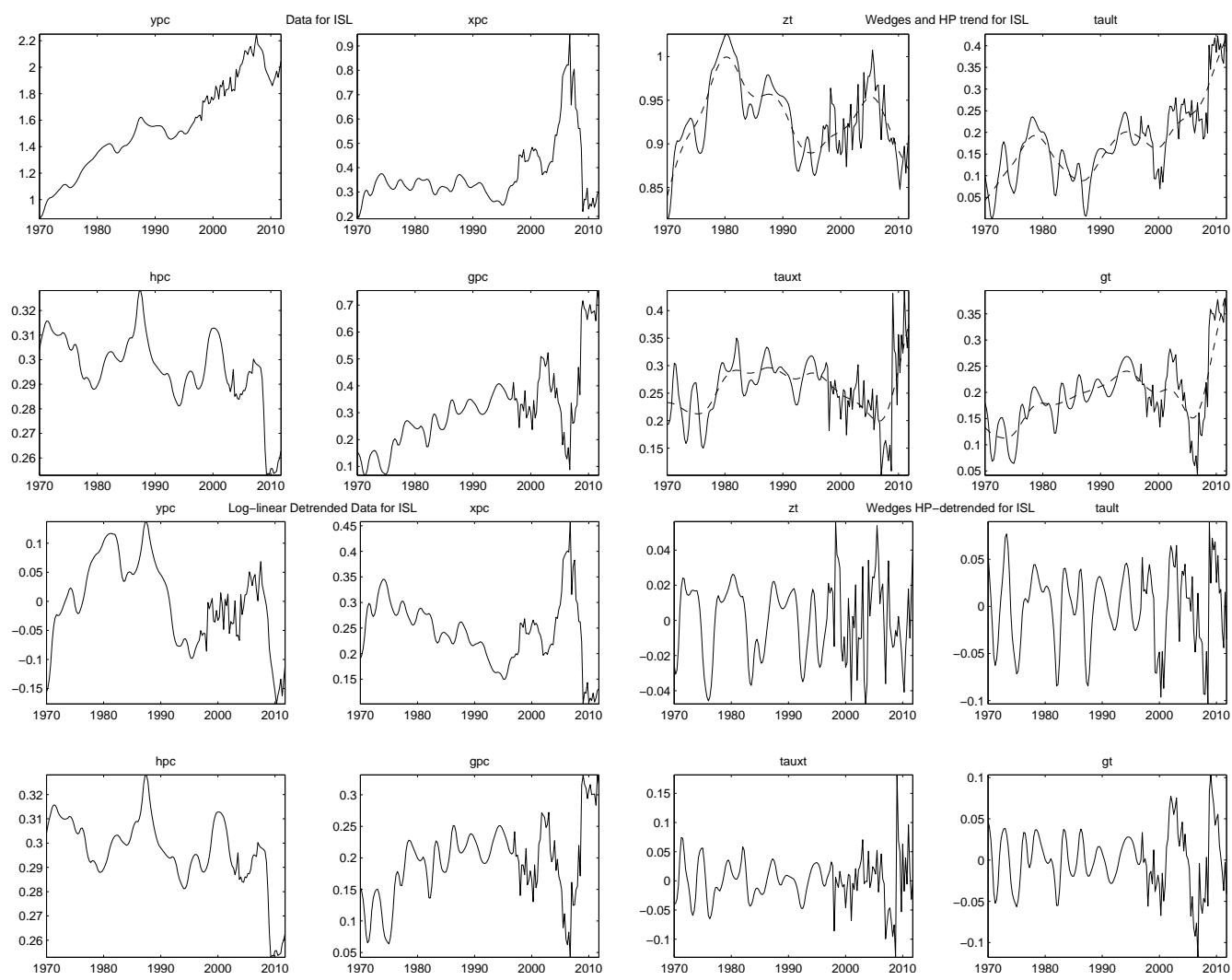


\section{Italy}
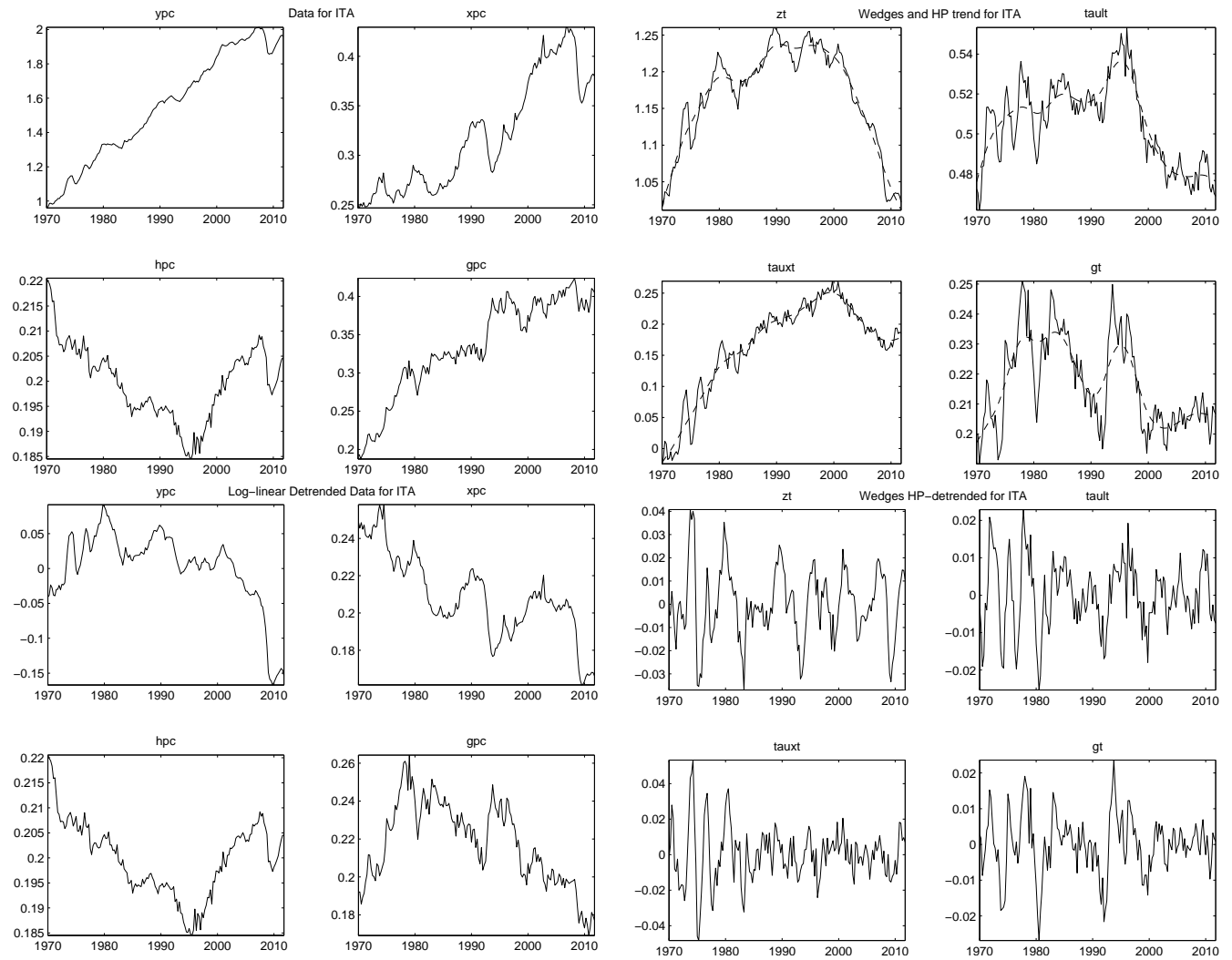

\section{Japan}
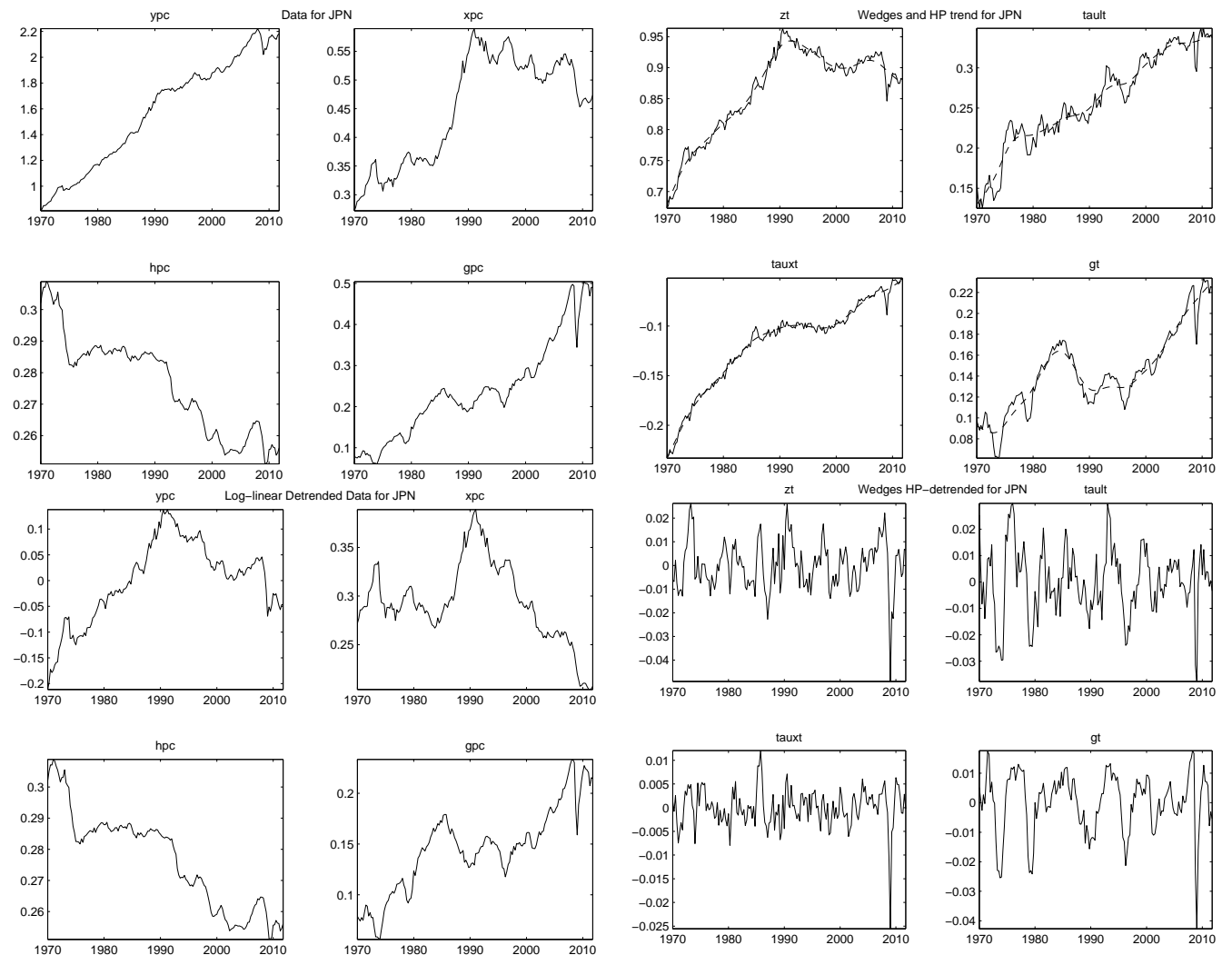


\section{South Korea}
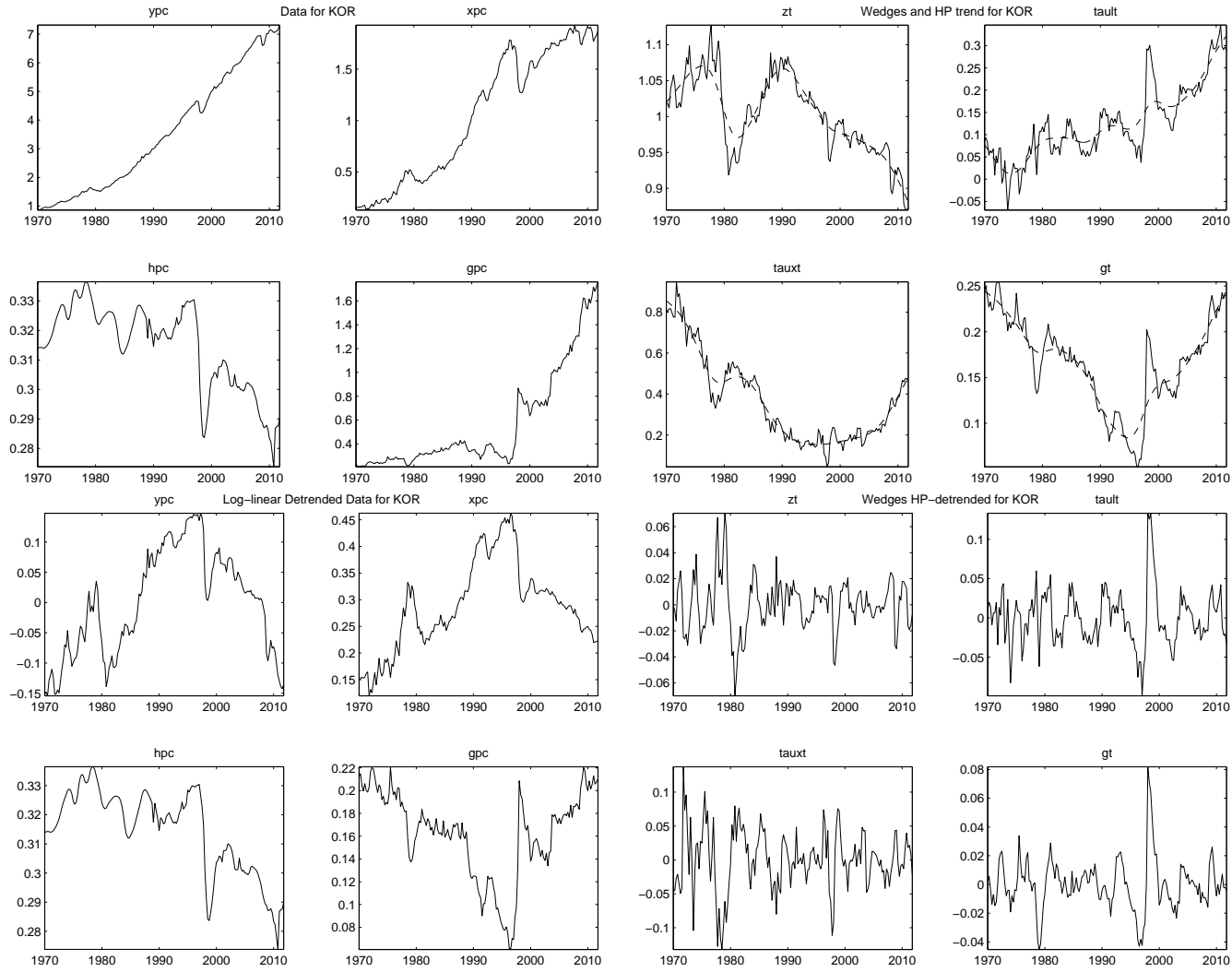

\section{Luxembourg}
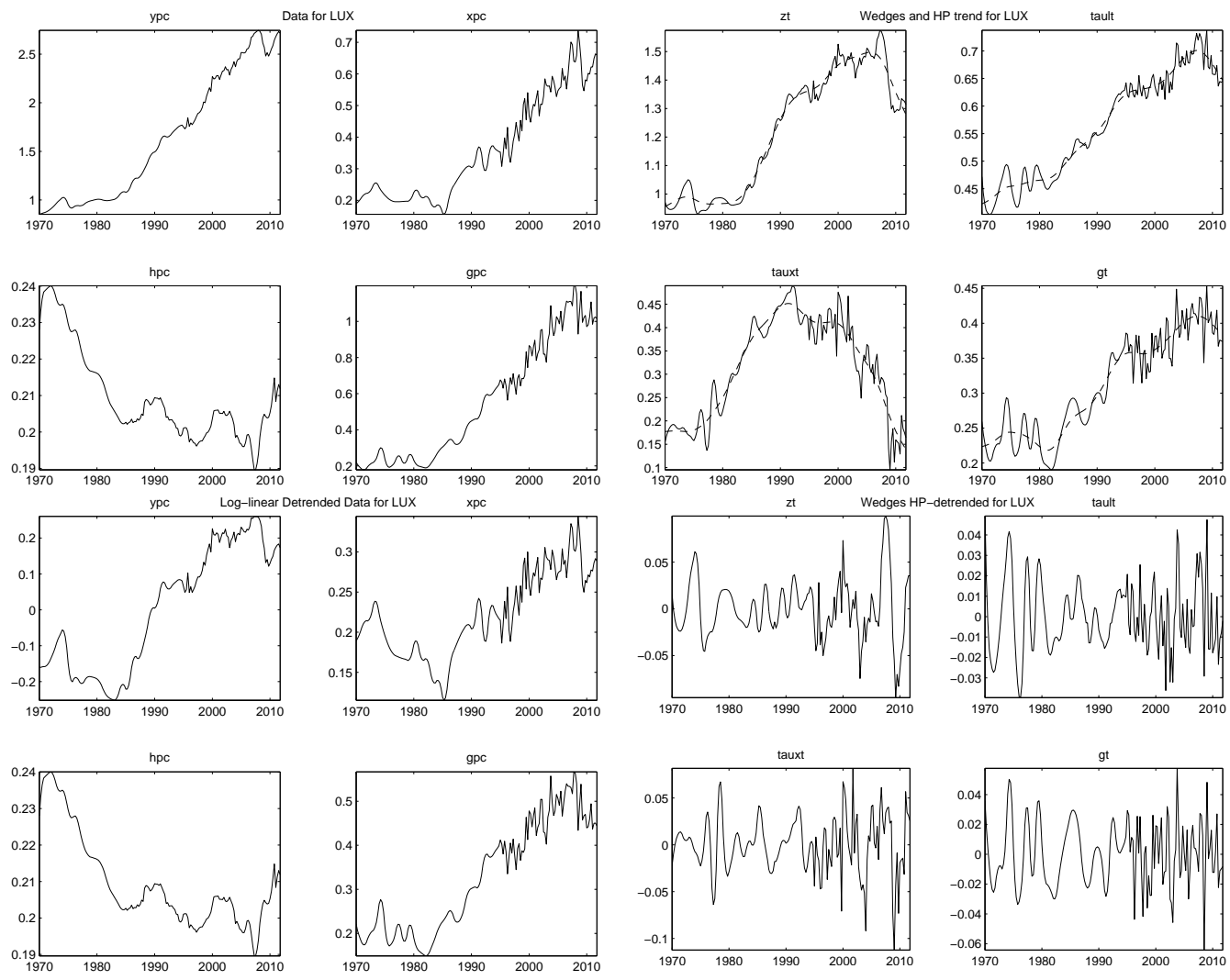


\section{Netherlands}
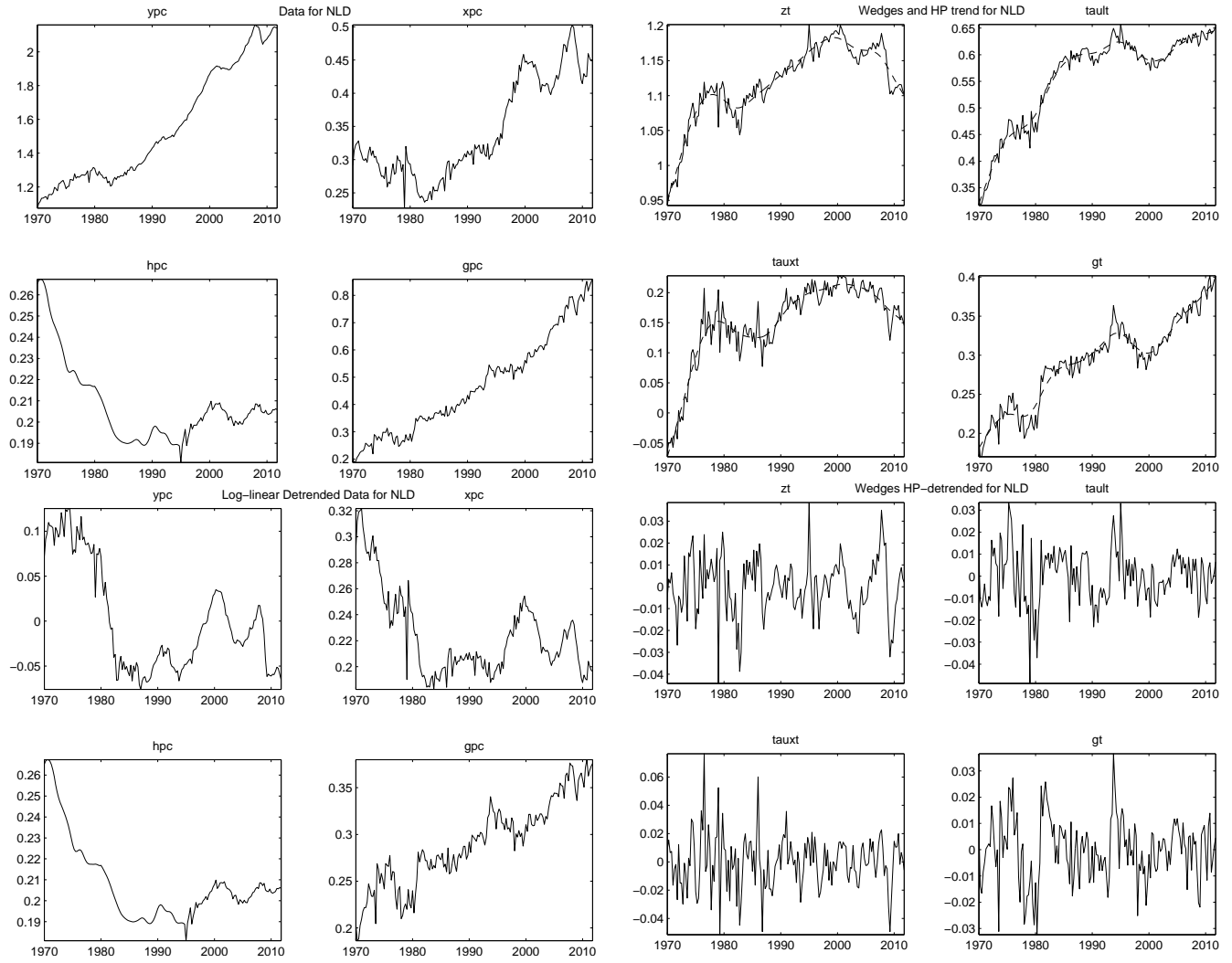

\section{Norway}
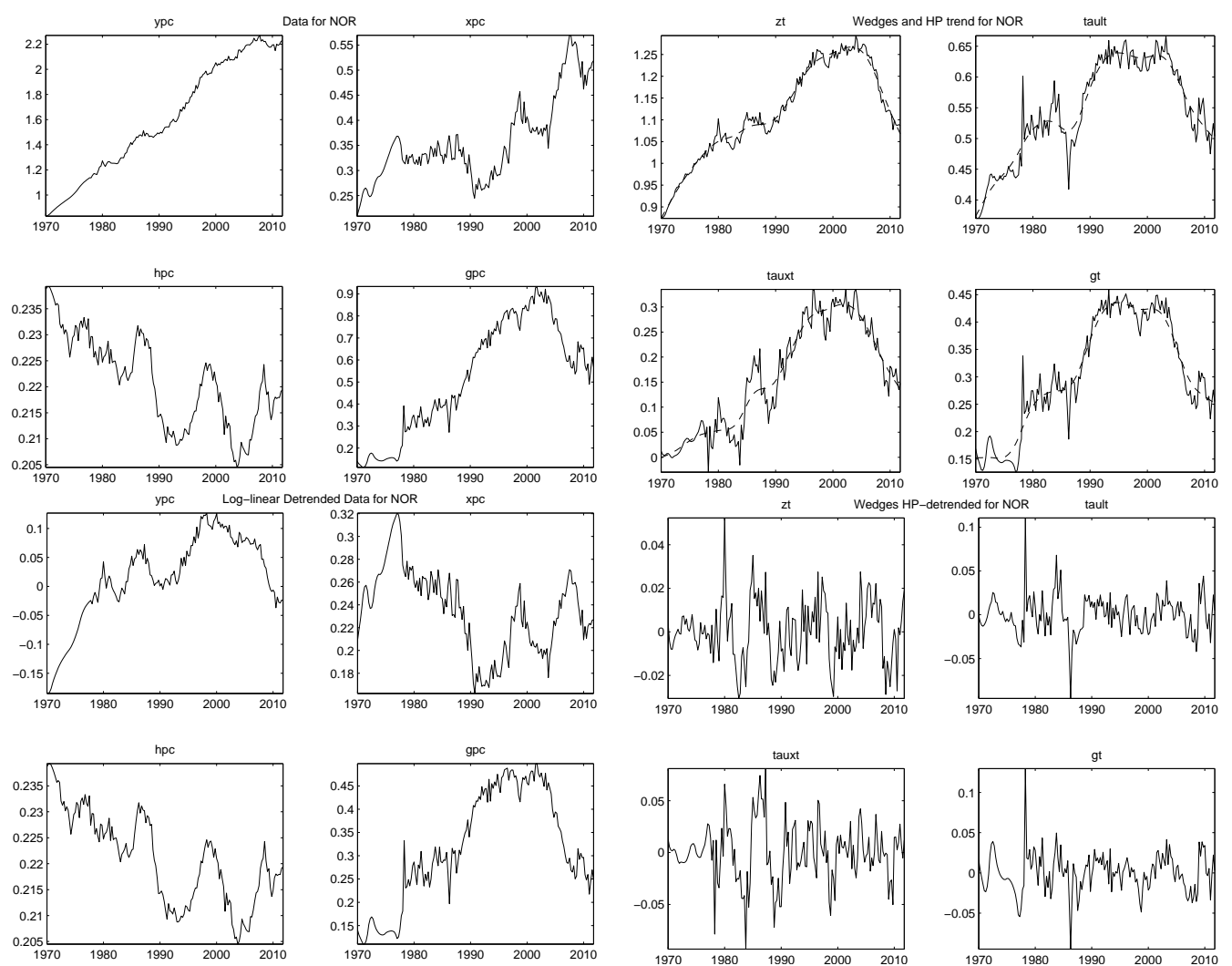


\section{New Zealand}
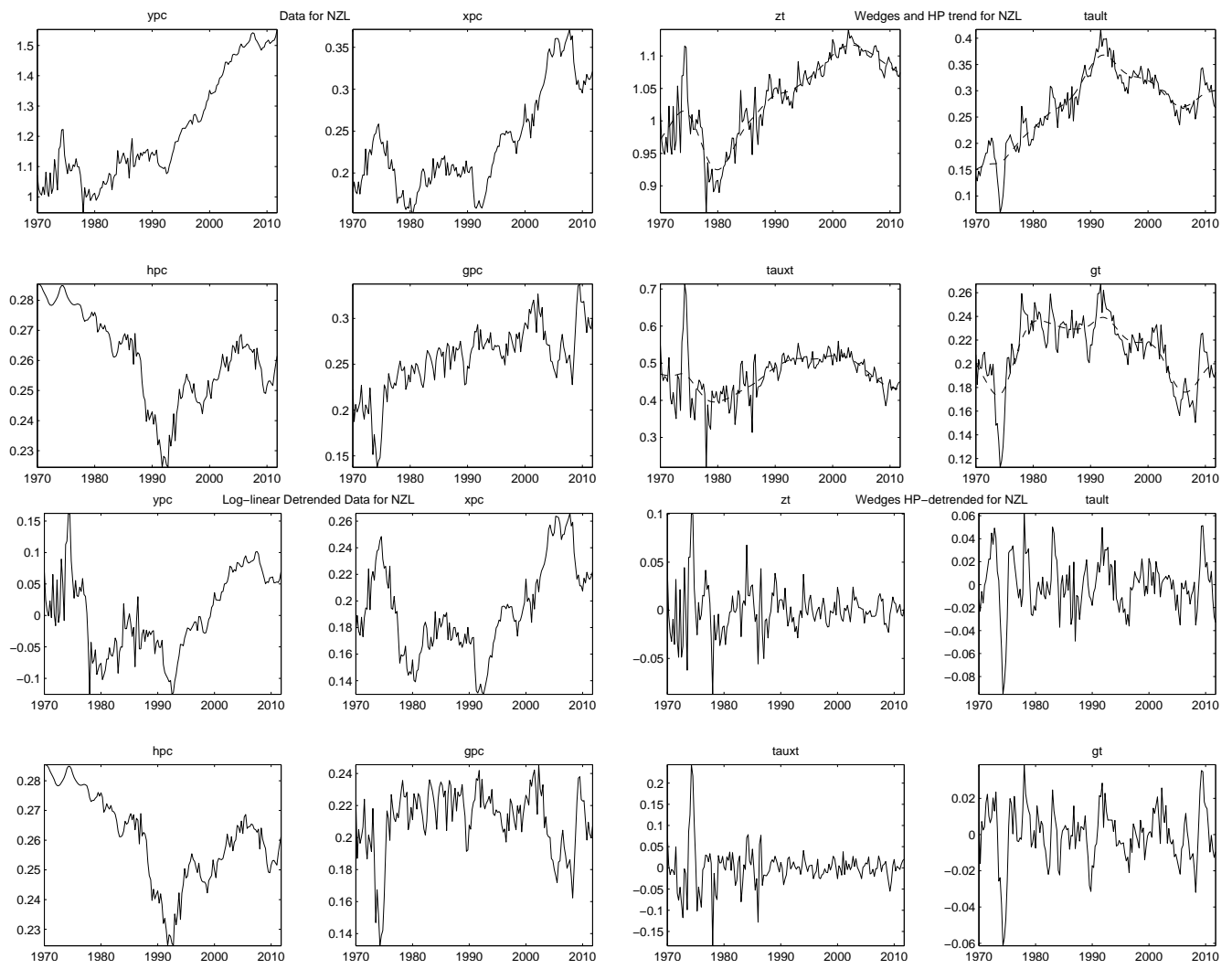

\section{Sweden}
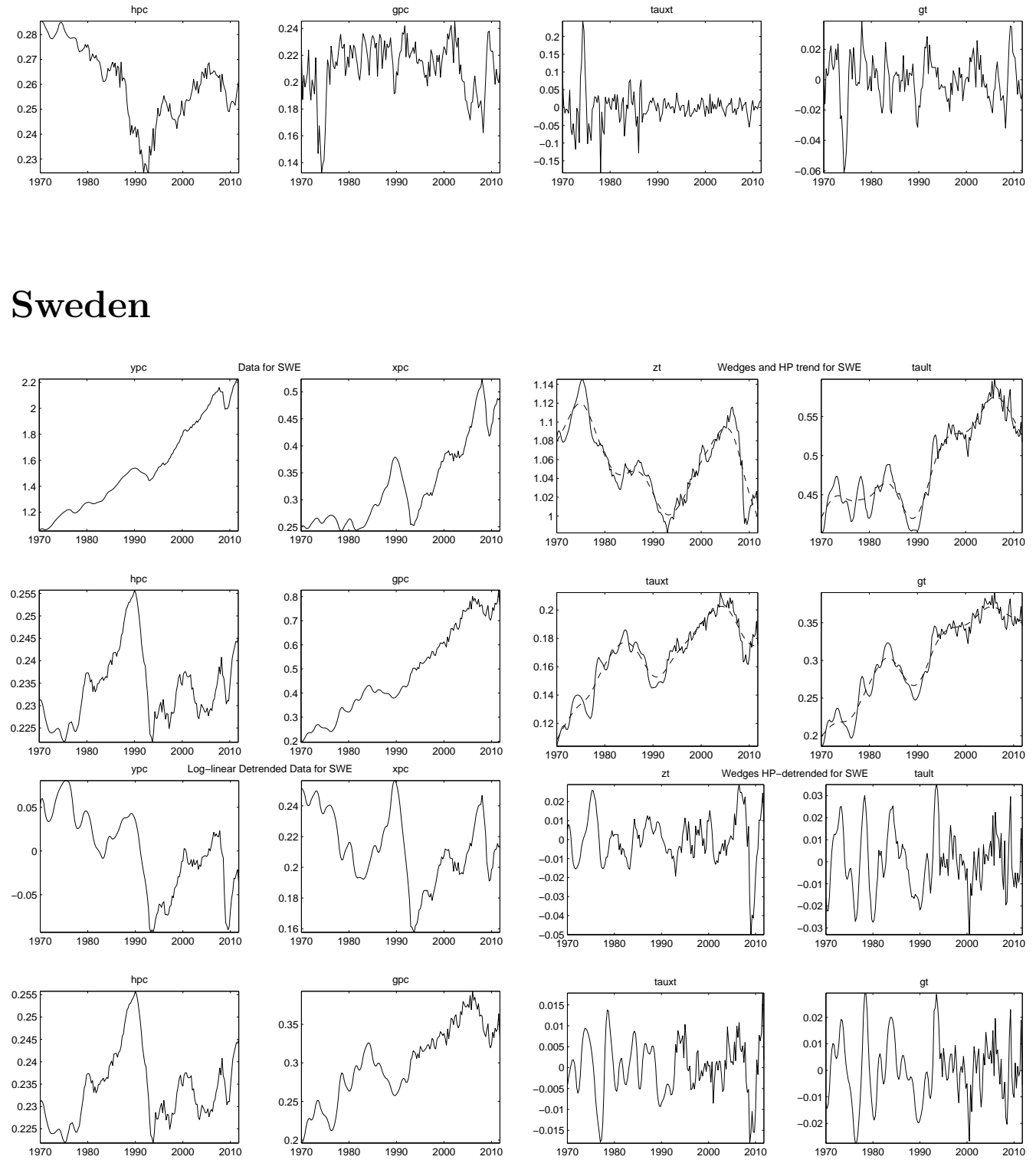


\section{USA}
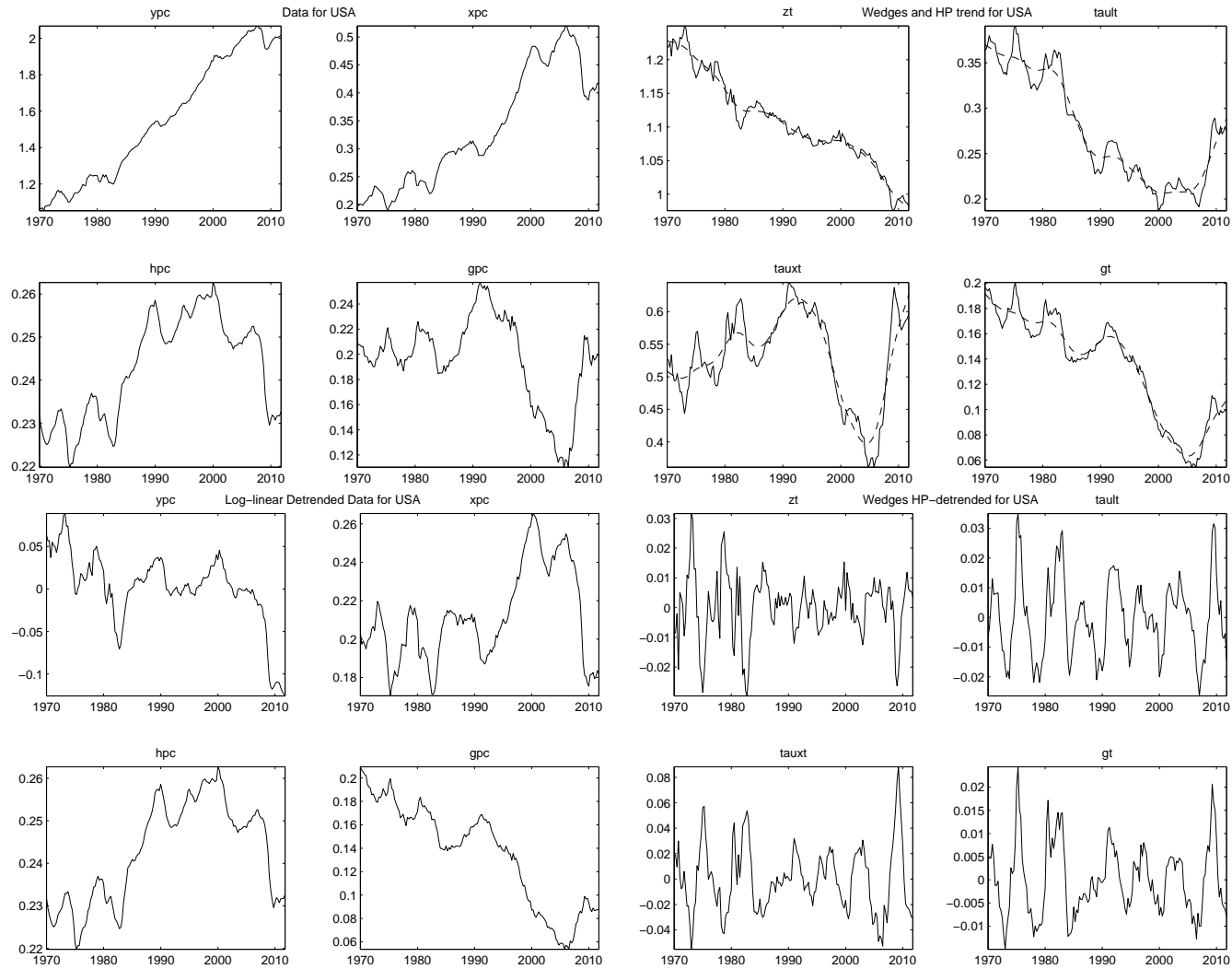

Appendix B - Simulations 


\section{Deviations from Cycle for 1 Wedge and 3 Wedge Economies}

Figure 1: Output
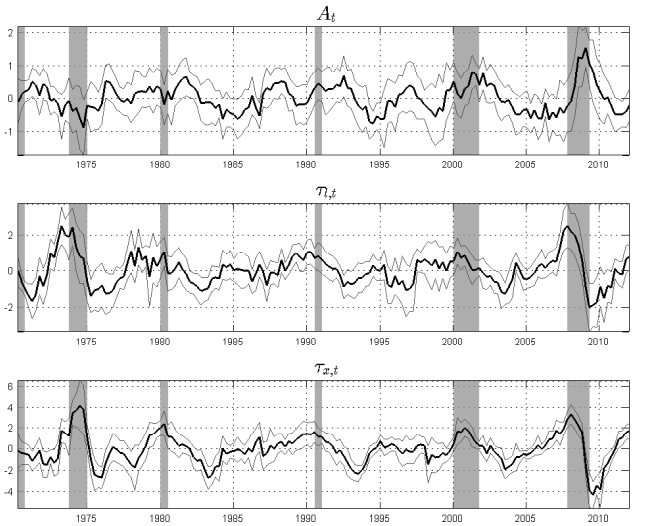

Figure 2: Hours worked
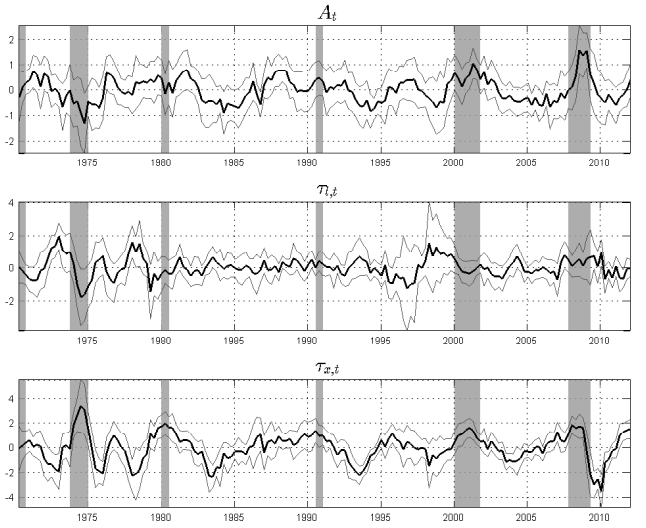

Figure 3: Investment
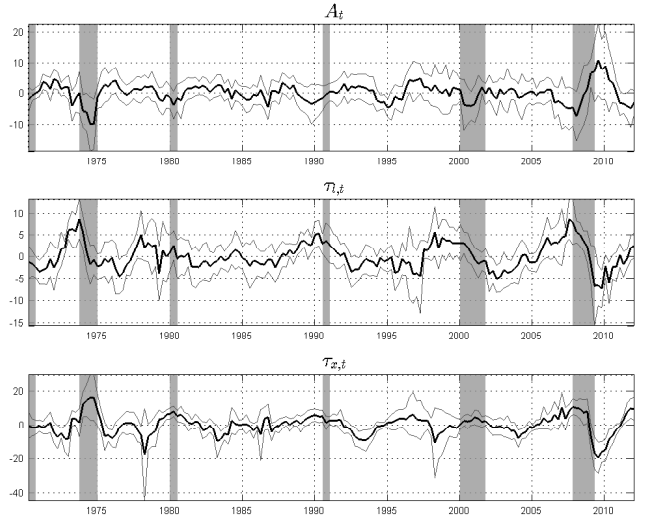

Figure 4: Output
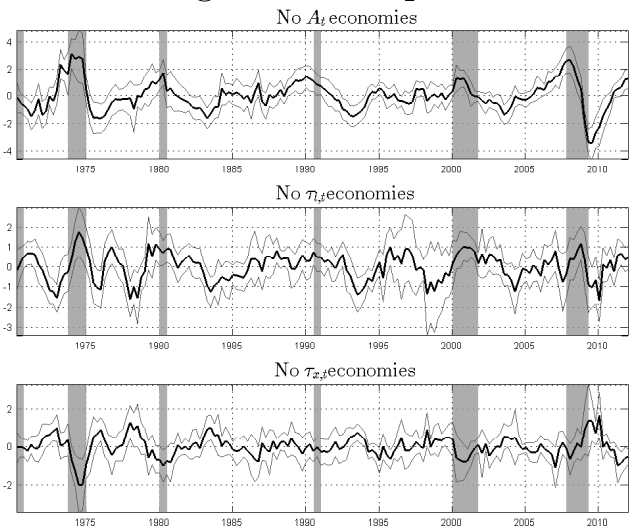

Figure 5: Hours worked
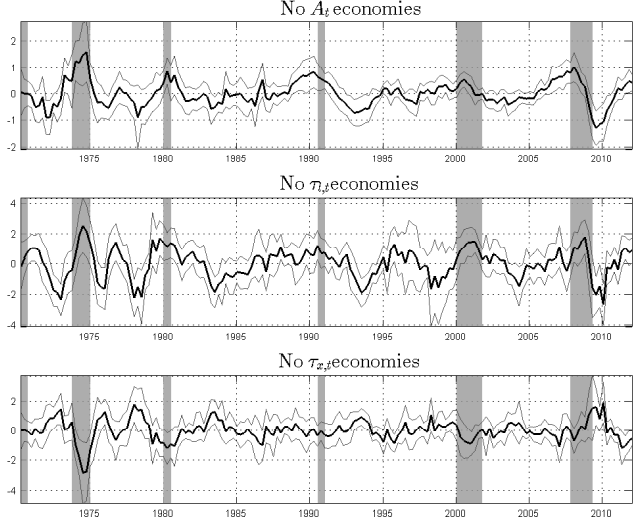

Figure 6: Investment
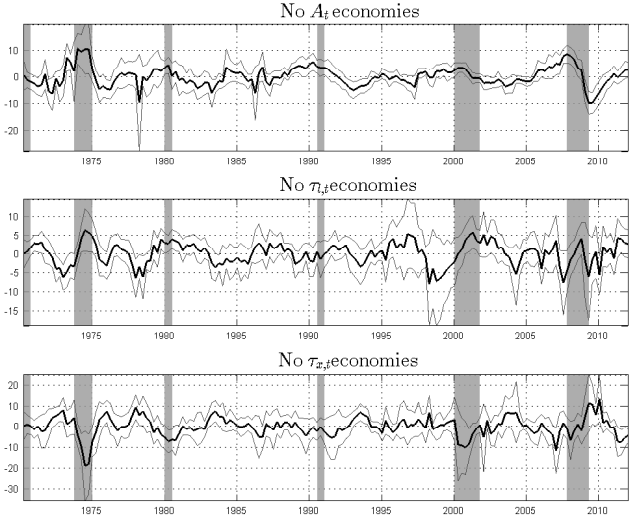


\section{RMSEs for 1 Wedge and 3 Wedge Economies}

Figure 7: Output

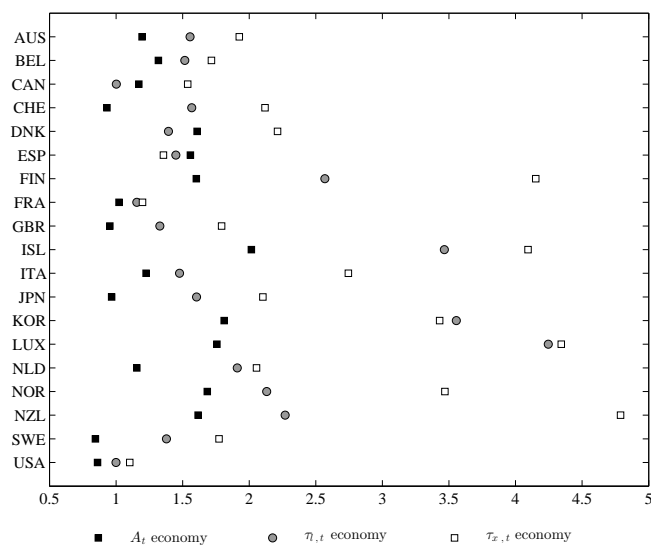

Figure 8: Hours worked

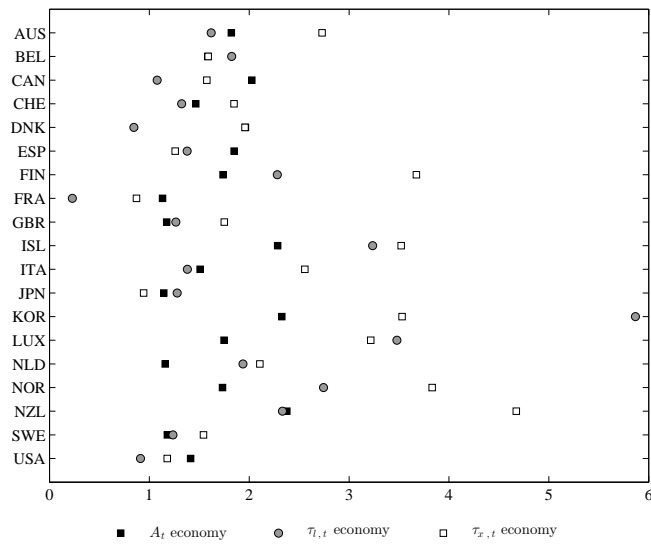

Figure 9: Investment

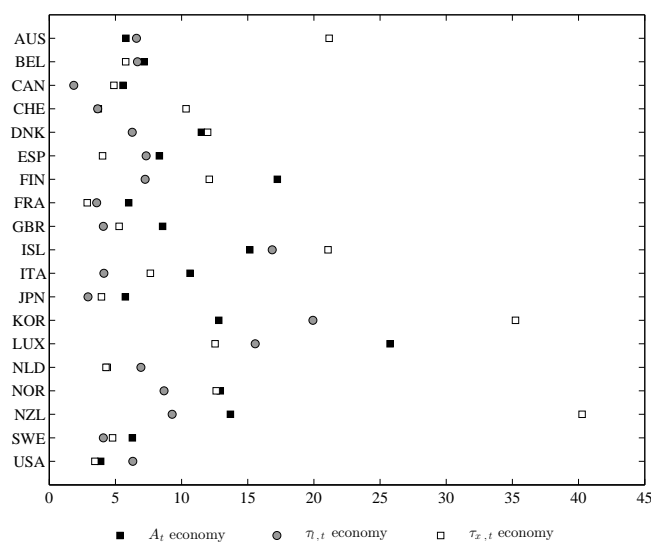

Figure 10: Output

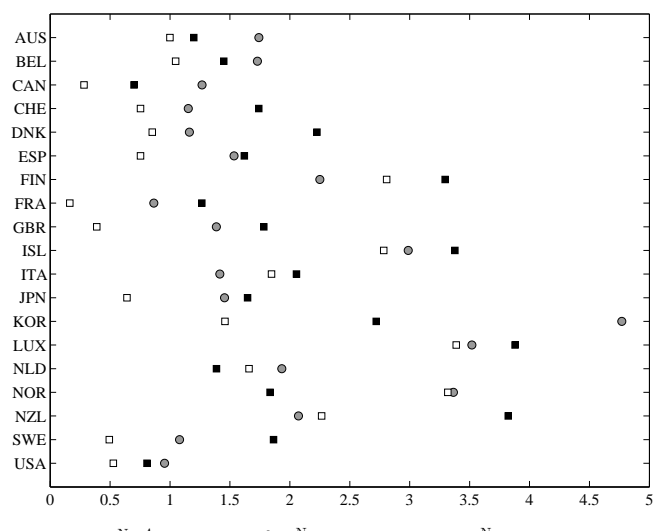

Figure 11: Hours worked

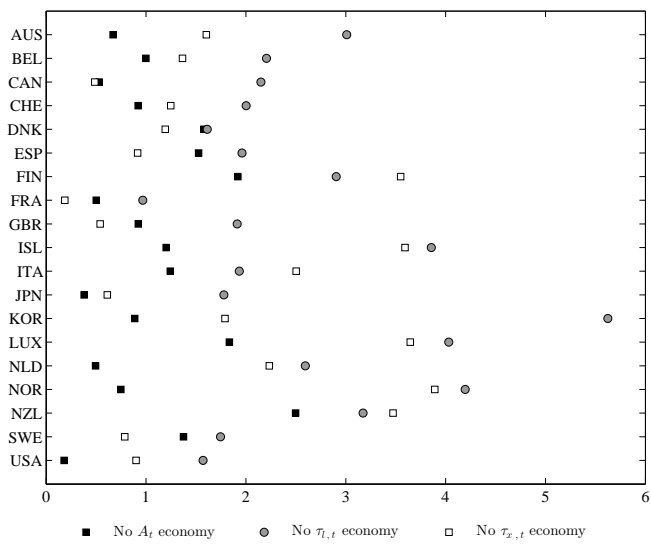

Figure 12: Investment

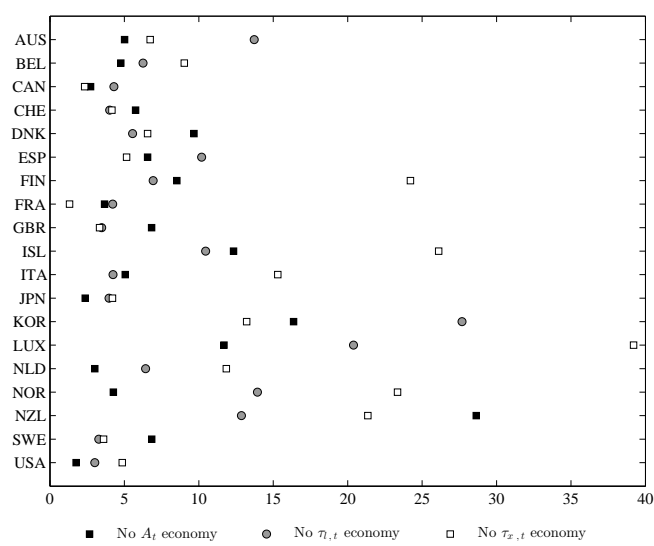




\section{Statistical Tests of Comparative Performance - RMSEs}

Table 1: Statistical Tests of Comparative Performance - 1 Wedge Economies Output

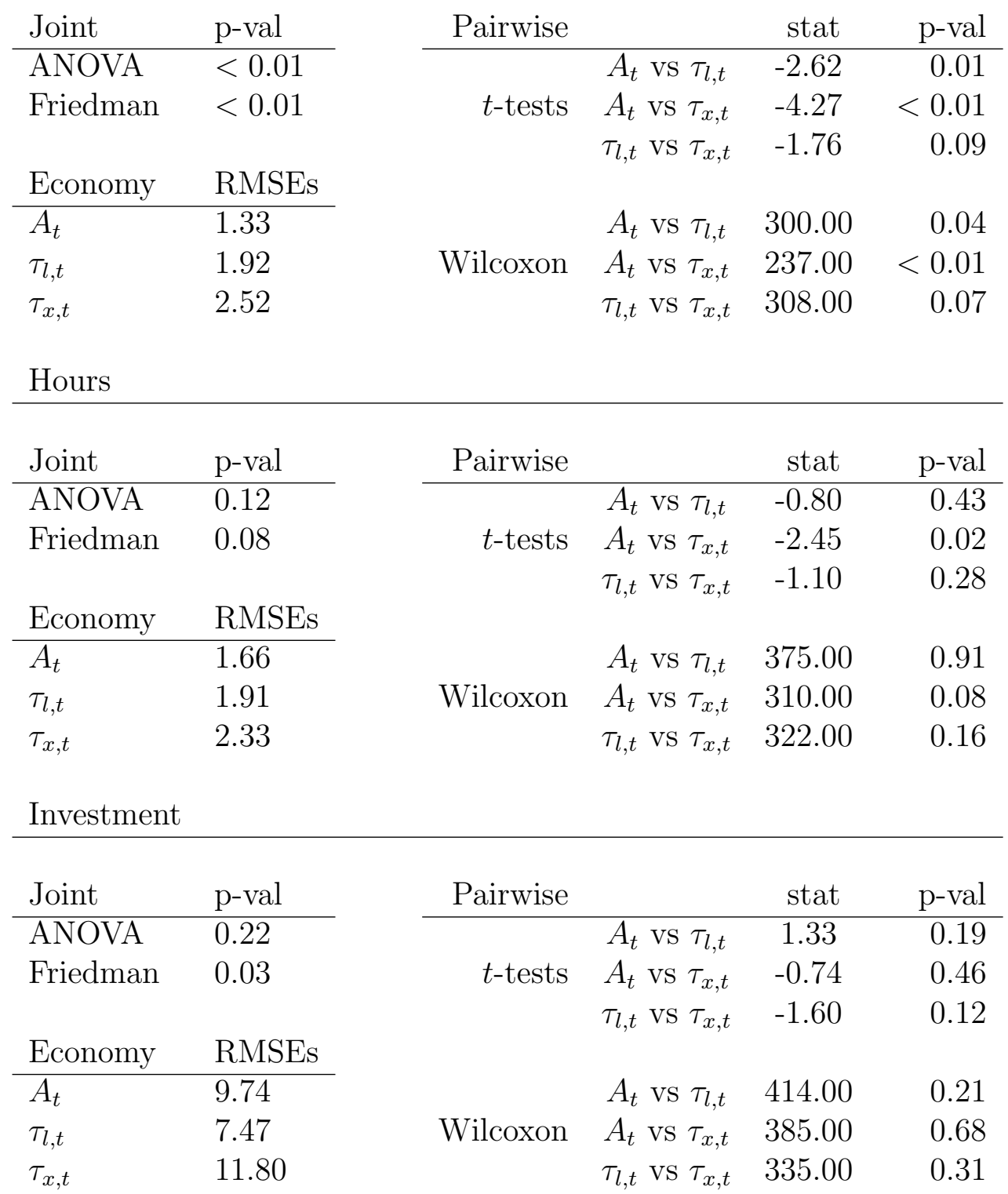


Table 2: Statistical Tests of Comparative Performance - 3 Wedge Economies Output

\begin{tabular}{|c|c|c|c|c|c|}
\hline Joint & p-val & Pairwise & & stat & p-val \\
\hline ANOVA & 0.12 & \multirow{6}{*}{ Wilcoxon } & No $A_{t}$ vs No $\tau_{l, t}$ & 0.33 & 0.74 \\
\hline \multirow[t]{2}{*}{ Friedman } & $<0.01$ & & No $A_{t}$ vs No $\tau_{x, t}$ & 1.98 & 0.06 \\
\hline & RMSEs & & No $\tau_{l, t}$ vs No $\tau_{x, t}$ & 1.59 & 0.12 \\
\hline No $A_{t}$ & 2.04 & & No $A_{t}$ vs No $\tau_{l, t}$ & 393.00 & 0.52 \\
\hline No $\tau_{l, t}$ & 1.93 & & No $A_{t}$ vs No $\tau_{x, t}$ & 441.00 & 0.04 \\
\hline No $\tau_{x, t}$ & 1.39 & & No $\tau_{l, t}$ vs No $\tau_{x, t}$ & 438.00 & 0.05 \\
\hline \multicolumn{6}{|l|}{ Hours } \\
\hline Joint & p-val & Pairwise & & stat & $\mathrm{p}$-val \\
\hline ANOVA & $<0.01$ & \multirow{6}{*}{ Wilcoxon } & No $A_{t}$ vs No $\tau_{l, t}$ & -5.07 & $<0.01$ \\
\hline \multirow[t]{2}{*}{ Friedman } & $<0.01$ & & No $A_{t}$ vs No $\tau_{x, t}$ & -2.32 & 0.03 \\
\hline & RMSEs & & No $\tau_{l, t}$ vs No $\tau_{x, t}$ & 1.98 & 0.06 \\
\hline No $A_{t}$ & 1.07 & & No $A_{t}$ vs No $\tau_{l, t}$ & 283.00 & 0.01 \\
\hline No $\tau_{l, t}$ & 2.59 & & No $A_{t}$ vs No $\tau_{x, t}$ & 243.00 & $<0.01$ \\
\hline No $\tau_{x, t}$ & 1.82 & & No $\tau_{l, t}$ vs No $\tau_{x, t}$ & 403.00 & 0.35 \\
\hline \multicolumn{6}{|l|}{ Investment } \\
\hline Joint & p-val & Pairwise & & stat & $\mathrm{p}$-val \\
\hline ANOVA & 0.25 & & No $A_{t}$ vs No $\tau_{l, t}$ & -0.48 & 0.64 \\
\hline \multirow[t]{2}{*}{ Friedman } & 0.53 & $t$-tests & No $A_{t}$ vs No $\tau_{x, t}$ & -1.50 & 0.14 \\
\hline & & & No $\tau_{l, t}$ vs No $\tau_{x, t}$ & -1.13 & 0.26 \\
\hline Economy & RMSEs & & & & \\
\hline No $A_{t}$ & 7.68 & & No $A_{t}$ vs No $\tau_{l, t}$ & 362.00 & 0.82 \\
\hline No $\tau_{l, t}$ & 8.68 & Wilcoxon & No $A_{t}$ vs No $\tau_{x, t}$ & 327.00 & 0.21 \\
\hline No $\tau_{x, t}$ & 11.89 & & No $\tau_{l, t}$ vs No $\tau_{x, t}$ & 346.00 & 0.48 \\
\hline
\end{tabular}




\section{Success Ratios for 1 Wedge and 3 Wedge Economies}

Figure 13: Output

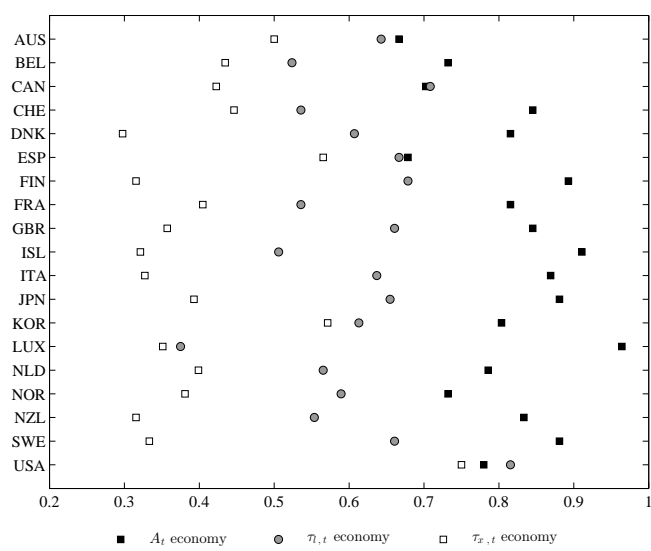

Figure 14: Hours worked

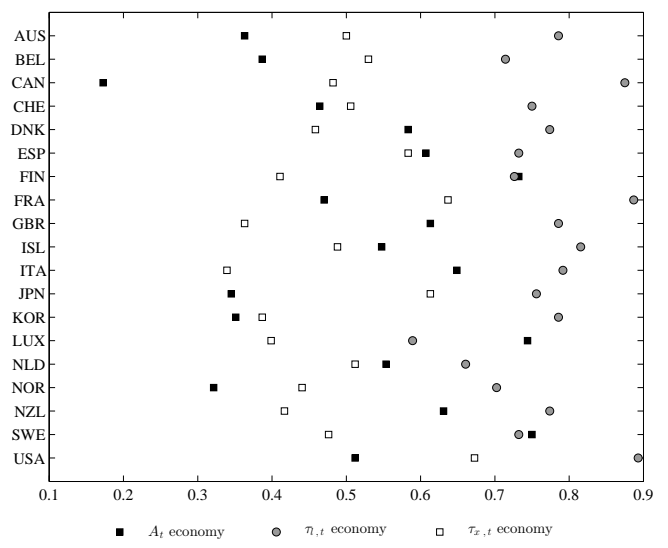

Figure 15: Investment

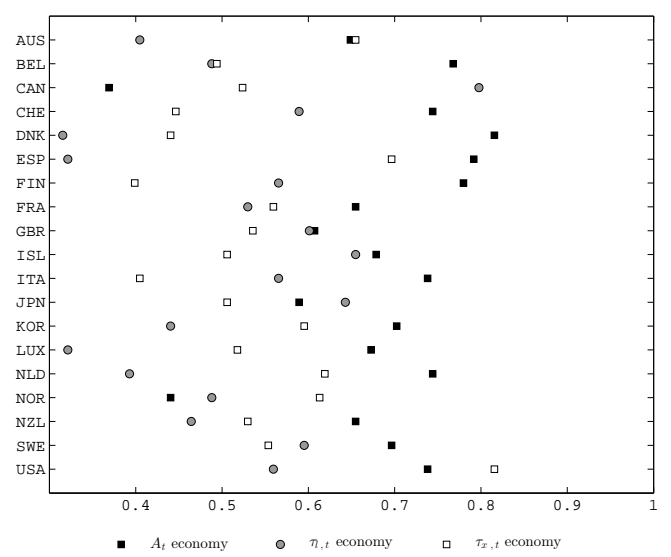

Figure 16: Output

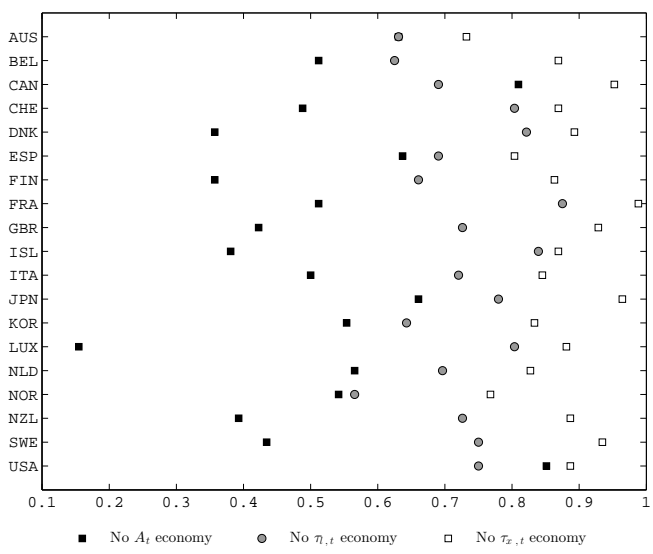

Figure 17: Hours worked

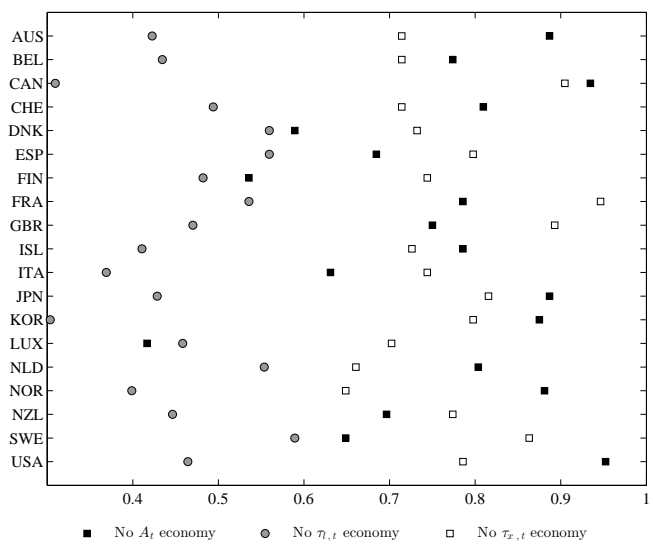

Figure 18: Investment

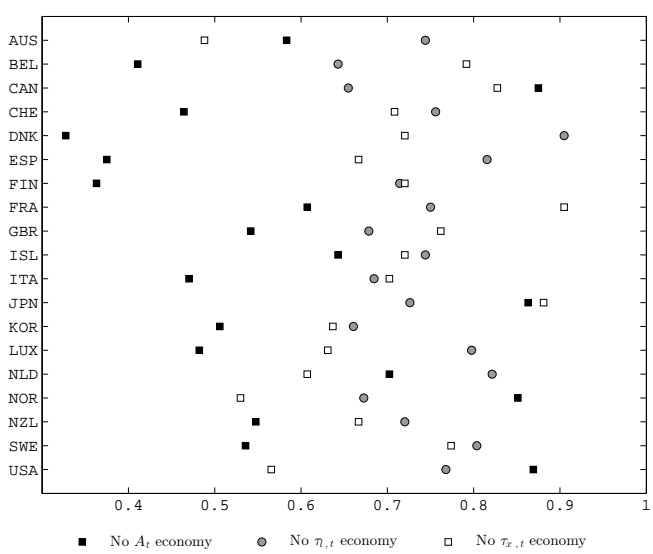




\section{Statistical Tests of Comparative Performance - SRs}

Table 3: Statistical Tests of Comparative Performance - 1 Wedge Economies Output

\begin{tabular}{|c|c|c|c|c|c|}
\hline Joint & p-val & Pairwise & & stat & p-val \\
\hline ANOVA & $<0.01$ & & $A_{t}$ vs $\tau_{l, t}$ & 7.19 & $<0.01$ \\
\hline Friedman & $<0.01$ & $t$-tests & $A_{t}$ vs $\tau_{x, t}$ & 12.34 & $<0.01$ \\
\hline & & & $\tau_{l, t}$ vs $\tau_{x, t}$ & 5.66 & $<0.01$ \\
\hline Economy & Success Ratios & & & & \\
\hline$A_{t}$ & $81 \%$ & & $A_{t}$ vs $\tau_{l, t}$ & 537.00 & $<0.01$ \\
\hline$\tau_{l, t}$ & $61 \%$ & Wilcoxon & $A_{t}$ vs $\tau_{x, t}$ & 546.00 & $<0.01$ \\
\hline$\tau_{x, t}$ & $42 \%$ & & $\tau_{l, t}$ vs $\tau_{x, t}$ & 511.50 & $<0.01$ \\
\hline
\end{tabular}

Hours

\begin{tabular}{|c|c|c|c|c|c|}
\hline Joint & p-val & Pairwise & & stat & p-val \\
\hline ANOVA & $<0.01$ & & $A_{t} \mathrm{vS} \tau_{l, t}$ & -6.12 & $<0.01$ \\
\hline Friedman & $<0.01$ & $t$-tests & $A_{t} \operatorname{vs} \tau_{x, t}$ & 0.72 & 0.48 \\
\hline Economy & Success Ratios & & $\tau_{l, t}$ VS $\tau_{x, t}$ & 10.26 & $<0.01$ \\
\hline$A_{t}$ & $52 \%$ & & $A_{t}$ vs $\tau_{l, t}$ & 214.50 & $<0.01$ \\
\hline$\tau_{l, t}$ & $76 \%$ & Wilcoxon & $A_{t} \operatorname{vs} \tau_{x, t}$ & 395.50 & 0.47 \\
\hline$\tau_{x, t}$ & $48 \%$ & & $\tau_{l, t} \operatorname{vs} \tau_{x, t}$ & 547.00 & $<0.01$ \\
\hline
\end{tabular}

\begin{tabular}{ll} 
Joint & $\mathrm{p}$-val \\
\hline ANOVA & $<0.01$ \\
Friedman & $<0.01$ \\
& \\
Economy & Success Ratios \\
\hline$A_{t}$ & $68 \%$ \\
$\tau_{l, t}$ & $51 \%$ \\
$\tau_{x, t}$ & $55 \%$
\end{tabular}

\begin{tabular}{rlrr} 
Pairwise & & stat & p-val \\
\hline \multirow{4}{*}{-tests } & $A_{t}$ vs $\tau_{l, t}$ & 4.15 & $<0.01$ \\
& $A_{t}$ vs $\tau_{x, t}$ & 3.62 & $<0.01$ \\
& $\tau_{l, t}$ vs $\tau_{x, t}$ & -0.94 & 0.35 \\
& & & \\
Wilcoxon & $A_{t}$ vs $\tau_{l, t}$ & 497.00 & $<0.01$ \\
& $A_{t}$ vs $\tau_{x, t}$ & 482.50 & $<0.01$ \\
& $\tau_{l, t}$ vs $\tau_{x, t}$ & 345.00 & 0.47
\end{tabular}


Table 4: Statistical Tests of Comparative Performance - 3 Wedge Economies Output

\begin{tabular}{|c|c|c|c|c|c|}
\hline Joint & p-val & Pairwise & & stat & p-val \\
\hline ANOVA & $<0.01$ & & No $A_{t}$ vs No $\tau_{l, t}$ & -5.06 & $<0.01$ \\
\hline \multirow[t]{2}{*}{ Friedman } & $<0.01$ & $t$-tests & No $A_{t}$ vs No $\tau_{x, t}$ & -8.90 & $<0.01$ \\
\hline & & & No $\tau_{l, t}$ vs No $\tau_{x, t}$ & -6.16 & $<0.01$ \\
\hline Economy & Success Ratios & & & & \\
\hline No $A_{t}$ & $51 \%$ & & No $A_{t}$ vs No $\tau_{l, t}$ & 234.50 & $<0.01$ \\
\hline No $\tau_{l, t}$ & $73 \%$ & Wilcoxon & No $A_{t}$ vs No $\tau_{x, t}$ & 199.00 & $<0.01$ \\
\hline No $\tau_{x, t}$ & $87 \%$ & & No $\tau_{l, t}$ vs No $\tau_{x, t}$ & 217.00 & $<0.01$ \\
\hline Hours & & & & & \\
\hline
\end{tabular}

\begin{tabular}{ll} 
Joint & $\mathrm{p}$-val \\
\hline ANOVA & $<0.01$ \\
Friedman & $<0.01$
\end{tabular}

\begin{tabular}{rlrr} 
Pairwise & & stat & p-val \\
\hline \multirow{4}{*}{$t$-tests } & No $A_{t}$ vs No $\tau_{l, t}$ & 7.87 & $<0.01$ \\
& No $A_{t}$ vs No $\tau_{x, t}$ & -0.49 & 0.63 \\
& No $\tau_{l, t}$ vs No $\tau_{x, t}$ & -11.91 & $<0.01$ \\
& & & \\
Wo $A_{t}$ vs No $\tau_{l, t}$ & 283.00 & 0.01 \\
Wilcoxon & No $A_{t}$ vs No $\tau_{x, t}$ & 243.00 & $<0.01$ \\
& No $\tau_{l, t}$ vs No $\tau_{x, t}$ & 403.00 & 0.35
\end{tabular}

Investment

\begin{tabular}{|c|c|c|c|c|c|}
\hline Joint & p-val & Pairwise & & stat & p-val \\
\hline$\overline{A N O V A}$ & $<0.01$ & & No $A_{t}$ vs No $\tau_{l, t}$ & -3.66 & $<0.01$ \\
\hline \multirow[t]{2}{*}{ Friedman } & 0.01 & $t$-tests & No $A_{t}$ vs No $\tau_{x, t}$ & -2.50 & 0.02 \\
\hline & & & No $\tau_{l, t}$ vs No $\tau_{x, t}$ & 1.33 & 0.19 \\
\hline Economy & Success Ratios & & & & \\
\hline No $A_{t}$ & $58 \%$ & & No $A_{t}$ vs No $\tau_{l, t}$ & 268.50 & $<0.01$ \\
\hline No $\tau_{l, t}$ & $74 \%$ & Wilcoxon & No $A_{t}$ vs No $\tau_{x, t}$ & 286.00 & 0.01 \\
\hline No $\tau_{x, t}$ & $70 \%$ & & No $\tau_{l, t}$ vs No $\tau_{x, t}$ & 415.00 & 0.20 \\
\hline
\end{tabular}

